Check for updates

Cite this: Mater. Adv., 2021, 2,7210

Received 17th September 2021 Accepted 17th October 2021

DOI: 10.1039/d1ma00859e

rsc.li/materials-advances

\section{Blood apheresis technologies - a critical review on challenges towards efficient blood separation and treatment}

\author{
Christine Jurene O. Bacal, (D) *ab James W. Maina, (D) ${ }^{\mathrm{b}}$ Harshal H. Nandurkar, ${ }^{\mathrm{c}}$ \\ Maryam Khaleel, (D) def Rosanne Guijt, (D) ${ }^{g}$ Yung Chang, (D) ${ }^{h}$ Karen M. Dwyer ${ }^{a}$ and \\ Ludovic F. Dumée (D)*def
}

\begin{abstract}
Blood apheresis technologies are crucial during blood donation and toxin removal. Current purification methods such as leukocytapheresis, erythrocytapheresis, thrombocytapheresis and plasmapheresis primarily rely on centrifugation and membrane filtration to separate blood components. Although established and scaled-up, challenges related to the selectivity and long-term impact of these techniques on blood cells and their constituents remain. Shear generated during extraction may stress blood cells leading to cell damage and initiate the complement cascade causing platelet activation or triggering inflammatory responses. Emerging technologies, including microfluidics and selective adsorption present viable alternatives supporting more selective extraction pathways but extensively rely on novel manufacturing or material developments. This review critically assesses recent progress across apheresis technologies relating to advances in surface science and materials engineering to address operating challenges towards selective removal or extraction of blood components in traditional apheresis technologies such as centrifugation and membrane filtration.
\end{abstract}

${ }^{a}$ Deakin University, Geelong, School of Medicine, Waurn Ponds, 3216, Victoria, Australia. E-mail: cbacal@deakin.edu.au

${ }^{b}$ Deakin University, Geelong, Institute for Frontier Materials, Waurn Ponds, 3216, Victoria, Australia

${ }^{c}$ Alfred Health, Australian Centre for Blood Diseases, Monash University, Melbourne, 3004, Victoria, Australia

${ }^{d}$ Department of Chemical Engineering, Khalifa University, Abu Dhabi, United Arab Emirates. E-mail: ludovic.dumee@ku.ac.ae

${ }^{e}$ Center for Membrane and Advanced Water Technology, Khalifa University, Abu Dhabi, United Arab Emirates

${ }^{f}$ Research and Innovation Center on $\mathrm{CO}_{2}$ and Hydrogen, Khalifa University, Abu Dhabi, United Arab Emirates

${ }^{g}$ Centre for Rural and Regional Futures, Deakin University, Geelong, VIC 3220, Australia

${ }^{h} R \& D$ Center for Membrane Technology and Department of Chemical Engineering, Chung Yuan Christian University, Chung-Li, 32023, Taiwan



Christine Jurene O. Bacal
Christine Jurene O. Bacal finished her undergraduate degree in Chemistry in the University of the Philippines - Diliman and took up her Masters in the same university. During her Masters, she specialized in bioprospecting of local fungal endophytes for carbohydrate-active enzymes (CAZys). Currently, she is a PhD candidate of both the School of Medicine (SoM) and the Institute for Frontier Materials (IFM) at Deakin University, Australia. Her research is now focused on developing a more selective haemodialysis membrane for acetaminophen overdose patients.

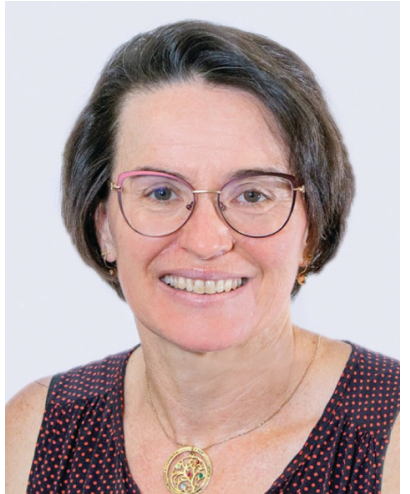

Karen M. Dwyer
Prof. Dwyer has more than 20 years clinical experience in the diagnosis and management of renal-related disease, including acute and chronic kidney injury, refractory hypertension and renal transplantation. Her research interests focus on purinergic signalling, specifically the role of CD39 and adenosine signalling in health and disease. She has developed small animal models to examine acute and chronic ischaemic induced kidney injury, and renal, liver and islet transplant related injury. Prof. Dwyer also has an interest in clinical research project specifically surrounding the diabetes arising post transplantation. 


\section{Introduction}

Blood is an essential biological fluid containing several blood cell types, such as red (RBCs), white (WBCs) blood cells and platelets, all contained in plasma as the liquid component enabling the transfer of the blood throughout the body. ${ }^{1}$ Abnormalities in these blood components can lead to various blood diseases necessitating treatment known as apheresis.

Apheresis is an extracorporeal medical procedure that involves removal of blood components temporarily utilizing centrifugal force, size and structural differences of blood components and surface forces in microchannels as basis of separation. ${ }^{2-5}$ Apheresis has two types based on purpose therapeutic and diagnostic. ${ }^{6}$ In therapeutic apheresis, diseasecausing blood components were removed in critically ill patients. ${ }^{7,8}$ Therapeutic apheresis techniques are utilized to treat patients with multiple myeloma, ${ }^{9}$ thrombotic thrombocytopenic purpura (TTP) (formation of blood clots in small blood vessels), ${ }^{10,11}$ neurological diseases, ${ }^{12}$ end-stage renal disease (ESRD) ${ }^{3,13}$ as well as drug toxicities. ${ }^{14,15}$ Meanwhile, diagnostic apheresis involves isolation of blood components for disease prognosis ${ }^{16}$ and is typically applied in cancer research. ${ }^{17}$ For instance, mononuclear cells (MNC) which are of low abundance (only $\sim 0.06 \%$ of all blood cells), are often separated from the bloodstream using diagnostic apheresis techniques without the need of biopsy (a procedure that involves taking a tissue specimen from the patient for the purpose of diagnosing a disease). ${ }^{16}$

Apheresis procedures may also be classified based on the types of blood component to be extracted, and include erythrocytapheresis and leukapheresis for respectively RBC and WBC extraction, and thrombocytapheresis and plasmapheresis for the collection of platelets and blood plasma respectively. ${ }^{18}$ The apheresis procedure remains challenging due to the complexity of blood matrix, the variations in blood composition between donors ${ }^{19}$ and risks of inducing cell damage. ${ }^{20}$ Apheresis techniques

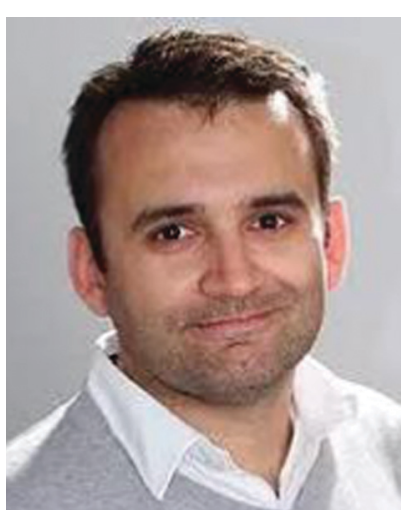

Ludovic F. Dumée
Ludo is an Assistant Professor at Khalifa University, Abu Dhabi, United Arab Emirates. His work is focused on the development of advanced separation materials stemming from the properties of nanoscale materials. His team investigates routes to generate efficient separation membranes and catalysts from $1 D$ and $2 D$ nanomaterials toward the design of isoporous membranes for ultra-selective separation of cells, proteins, and pollutants.

He is active in developing innovative separation technologies with lower operating costs and footprint to support Circular Economy strategies. can affect cell integrity and biological function ${ }^{21,22}$ due to the shear stress experienced during the extraction processes. In addition, only a limited number of different components can be collected simultaneously within a single apheresis procedure due to long treatment times which can lead to significant risks of blood contamination caused by transfusion-transmitted pathogens such as HIV, hepatitis B and C virus, prions, to name a few. ${ }^{23}$ The most mature and clinically implemented technologies enabling blood apheresis include centrifugation and membrane filtration. ${ }^{9}$ Progress in terms of equipment capabilities, separation material biocompatibility and performance has led to increased shelf-life, greater purity of the extracted components as well as more rapid processing of larger blood volumes. ${ }^{24}$ Challenges related to platelet activation and biofouling during separation however still prevail, limiting the efficacy and utility of the procedure. ${ }^{24}$ Hence, an assessment of the efficiency of existing and emerging apheresis techniques in relation to ultra-selective blood component extraction is required, while considering the cost-effectiveness in more mature technologies. ${ }^{12}$ So far, limited studies described key performance characteristics of the existing apheresis technologies ${ }^{25-29}$ and few comprehensively benchmarked current practices to emerging and alternative technologies, such as microfluidic-based or sorbentbased apheresis. ${ }^{30}$ The impact of materials used or the operating parameters on the removal efficiency are also seldomly discussed. ${ }^{31}$ An analysis of the key performance characteristics of each apheresis techniques is therefore required ${ }^{27}$ and must be tailored to a specific disease indication..$^{32-34}$

This review discusses current blood apheresis technologies as well as emerging solutions and materials to separate specific components from blood. A comprehensive overview on the gaps remaining across these technologies in terms of extraction rate, separation yield, throughput and potential effects on cells will be presented. The performance and efficiency of these technologies, for both therapeutic and diagnostic apheresis techniques, will be assessed considering the improvements on surface characteristics, percentage of haemolysis and thrombogenicity. Fresh perspectives for further improvement of the technologies in terms of design and operating procedures, and perspectives towards integration of more efficient and biocompatible materials will also be offered.

\section{Centrifugal-based apheresis}

Differential centrifugation is the method used to separate blood components from whole blood based on their densities upon increasing either applied centrifugal force, spinning duration or number of centrifugal cycles. ${ }^{2}$ Plasma has the lowest density thus settles last, platelets and leukocytes have intermediate densities and erythrocytes have the highest density among the blood cell components hence settling first compared to other blood cells at the bottom of the tube (schematic diagram on Fig. 1a). ${ }^{2}$ Centrifugal-based apheresis is applicable during blood transfusions and isolation of blood 




Increasing centrifugal force

b

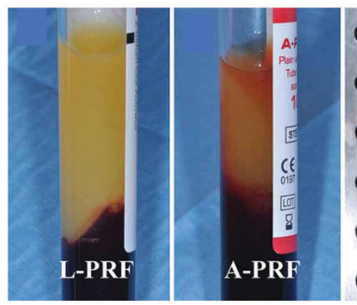

C



V20

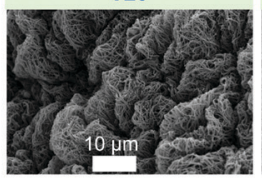

d

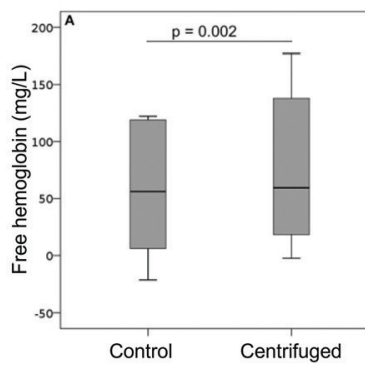

$\mathrm{H} 40$

V40

e
BLOOD

- Platelets

Leukocytes

Erythrocytes
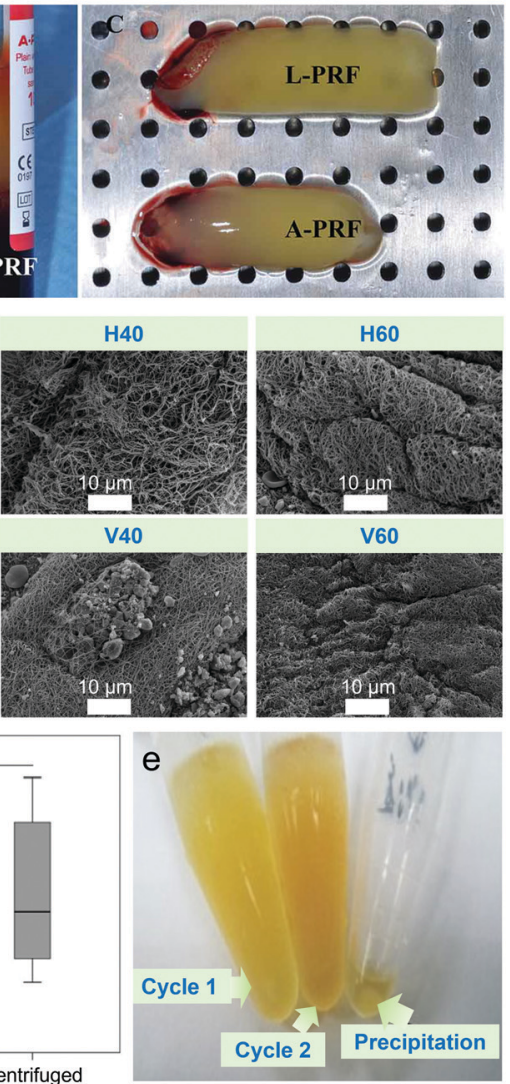

COMPONENTS

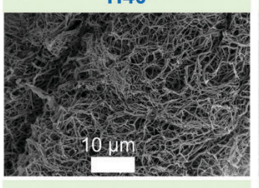

Fig. 1 Centrifugal-based apheresis. (a) Density-driven separation. Blood components are separated depending on the applied centrifugal force, spinning duration and number of centrifugal cycles. Yellow background represents blood plasma. (b) Impact of centrifugal force on separated blood components during centrifugation. ${ }^{36}$ Leukocyte- (L-PRF) and platelet-rich fibrin clot (A-PRF) centrifuged at $2700 \mathrm{rpm}$ for $12 \mathrm{~min}$ (A) and platelet-rich fibrin clot centrifuged at $1500 \mathrm{rpm}$ for $14 \mathrm{~min}$ (B) showed that yellow clot from A-PRF was not fully separated from the red blood cell part due to lower applied centrifugal force. (c) Impact of increasing centrifugal duration on separated blood components. Electron micrographs of fibrin scaffolds at $10000 \times$ magnification showed thicker and less dense filaments upon 20 min centrifugation than 40 and $60 \mathrm{~min}$ centrifugation. ${ }^{37}$ (d) Effect of centrifugation duration on free haemoglobin concentration. Free haemoglobin concentration $\left(\mathrm{g} \mathrm{L}^{-1}\right)$ measured for either 5 or 10 min showed the same result for control and centrifuged sample. ${ }^{21}$ (e) Impact of number of centrifugation cycles on microRNAs. ${ }^{38}$ Higher concentration of serum was observed at second centrifugation than the first cycle. Lower detection rates for microRNAs were observed after second centrifugation.

cells $^{26}$ and is the most utilized apheresis technique since it is versatile, fast to prime and set-up. ${ }^{27}$
The main challenge of using centrifugation-based apheresis is the occurrence of haemolysis, or rupture of blood cells, caused by shear stress introduced during spinning. ${ }^{35}$ The extent of haemolysis is dependent on centrifugal operating conditions such as operating mode to be used, centrifugal force, spinning duration and number of centrifugal cycles and will be discussed in this section.

\subsection{Operating modes}

There are two operating modes in centrifugal-based apheresis, which can either be manual or automatic. ${ }^{2}$ Manual centrifugation involves pelleting cells in a swinging bucket centrifuge and discarding the supernatant after the centrifugal process. ${ }^{39}$ Meanwhile, automatic centrifugation involves following a series of pre-set protocols from the centrifuge, depending on application with minimal user intervention. ${ }^{39}$ Sample recoveries for each operating mode are quantified and compared in the literature using the percentage (\%) in recovery, the volume recovered or the number of cells present in the supernatant before and after centrifugation. ${ }^{40}$ The separation efficiency is, however, a measurement of the amount of blood components extracted or collected within the shortest time possible without compromising the integrity of these components. ${ }^{25,26,41}$

The operation mode must therefore be selected carefully based on the type of cells to be separated to ensure high yields. Overall, in separating blood components for component collection using centrifugation, the yield of the peripheral blood stem cells (PBSC) during leukapheresis should be $2 \times 10^{6} \mathrm{CD} 34$ cells or $2 \times 10^{8}$ mononuclear cells (MNCS) per kg body weight of the recipient. ${ }^{41}$ Also, since packed red blood cells (PRBC) and platelet concentrates (PLTC) contain mostly leukocytes, the number of leukocytes must be $<1.2 \times 10^{9}$ if the entire buffy coat, corresponding to blood portion consisting mostly of leukocytes and platelets, is to be discarded. ${ }^{41}$

The impact of manual or automatic centrifugation on the absolute volume of red blood cells recovered was evaluated and it was observed that using manual centrifugation, $\sim 201 \pm$ $3 \mathrm{~mL}$ per blood unit from a starting volume of $240-300 \mathrm{~mL}$ per blood unit and centrifugal speed of $4200 \times g^{42}$ was recovered yielding a recovery range of $67-84 \%$. When automatic centrifugation was applied, the absolute red blood cell mass volume recovered stood at $\sim 214 \pm 0.6 \mathrm{~mL}$ per blood unit from a starting volume of $240-250 \mathrm{~mL}$ per blood unit ${ }^{42}$ giving a higher recovery range of $86-89 \%$. The recoveries of leukocytes and CD34+, a glycoprotein marker of blood stem cells, were also evaluated with both manual and automatic modes. Interestingly, no significant change in WBC count per kg dose recovery $(0.9 \pm 0.07)$ was obtained whether manual and automatic centrifugation were used. ${ }^{43}$ There was also no significant change in the CD34+ count per kg dose recovery $(0.9 \pm 0.09)$ when comparing both operation modes ${ }^{43}$ demonstrating the need to select techniques based on cost-effectiveness. In the same study that compared the recovery of WBCs and CD34+, the separation efficiency was also compared in terms of processing times. Although both centrifugal modes showed no significant differences in recoveries, the processing time for manual 
centrifugation (35 $\mathrm{min}$ ) was much longer than that of the automatic centrifugation ( $28 \mathrm{~min}$ ) for the same treated blood volume. ${ }^{43}$ Longer processing times also typically lead to platelet loss and clotting events ${ }^{25,44}$ thus this factor must also be considered aside from the cost.

The sample purity is also affected by the centrifugal operating mode. The application of manual centrifugation was found to lead to discrepancies in spin speeds while additional user manipulations may lead to large variations in the quality and purity of the separated blood component. ${ }^{45}$ Automatic centrifugation can produce separated blood components that are more uniform in composition since protocols are set based on the blood component to be separated with minimal user intervention. For instance, the percentage of haematocrit, corresponding to the ratio of red blood cells to whole blood, was compared for both manual and automatic modes of centrifugation. The measured \% haematocrit in manual mode was $73 \pm 9 \%$ compared to $89 \pm 7 \%$ for the automatic mode, demonstrating that purer red blood cells may be extracted with the latter. The purity variations can be attributed to the fact that manual centrifugation might induce greater mechanical shear stress to the sample due to the longer operating times, which may lead to platelet activation. ${ }^{46}$ The percentage of haemolysis, or blood cell lysis, corrected for haematocrit for both modes was evaluated and it was found that percentage of haemolysis was greater $(0.7 \pm 0.20)$ for manual centrifugation compared to automatic centrifugation $(0.4 \pm 0.2) .{ }^{42}$ Automatic centrifugation is therefore currently recommended unless cost prohibitive or additional user intervention is needed.

\subsection{Centrifugal force}

Centrifugal force, described to be either revolutions per minute (rpm) or relative centrifugal force ( $\mathrm{rcf}$ ) - also known as " $g$-force" $(\times g)$, is the apparent force pulling a blood component of interest away from the centre of rotation, caused by the component's inertia. ${ }^{9,41}$ Characterization of mechanical properties of blood components is important in diagnosing haematological disorders and optimizing the design of cardiovascular implants and blood circulating devices with respect to blood damage. ${ }^{21}$ A study discussed the effect of centrifugation on the markers of mechanical damage and RBC membrane. ${ }^{21}$ An increase in the free haemoglobin yield from $61 \mathrm{mg} \mathrm{L}^{-1}$ to $79 \mathrm{mg} \mathrm{L}^{-1}$ could be attributed to haemolytic damage caused by the forces associated with centrifugation, even at $900 \times g$.

Leukocyte- and platelet-rich fibrin clots (L-PRF) were also separated due to its significance in oral and maxillofacial regenerative therapies via centrifugation. ${ }^{36}$ It was observed that when centrifugal force applied increased from $1500 \mathrm{rpm}$ to $2700 \mathrm{rpm}$ for 14 and $12 \mathrm{~min}$ respectively, the separation between the clot and the red blood cell became more defined regardless of the blood volume used $(10 \mathrm{~mL}$ for $1500 \mathrm{rpm}$ and $9 \mathrm{~mL}$ for $2700 \mathrm{rpm}$ ) (Fig. 1b). Cell viability of adipocytes was observed when centrifuged from blood and it was discovered that there was no significant difference in the cell viability in the centrifuged adipocytes. ${ }^{47}$ After eight accelerations up to $20000 \times g$ for $10 \mathrm{~min}$, the viability remained at around
80-90\%. ${ }^{47}$ An increase in the centrifugal force alone could not be equated to higher purity samples. The level of plateletrich plasma obtained was 3.2 times that of the concentration of WB baseline when a centrifugal force of $200 \times g$ was used in $5 \mathrm{~mL}$ WB for two spins, $10 \mathrm{~min}$ each. ${ }^{48}$ Comparatively, a platelet concentration factor of 3.47 was obtained from an $8.5 \mathrm{~mL}$ processed WB when centrifugation was performed at both $130 \times g$ and $250 \times g$ for a period of $15 \mathrm{~min}$ when performing a two-spin centrifugation process. ${ }^{49}$ The centrifugation of WB at $460 \times g$ for 8 min using only one centrifugation spin step led to a platelet concentration factor of 2.67 above baseline. ${ }^{50}$ When around 5-6 L of blood were processed, effects of centrifugal force on the collection efficiency of mononuclear cells were evaluated using packing factor $(\mathrm{PF}) .{ }^{51}$ Packing factor is defined as the exertion of relatively high centrifugal force on the anticoagulated blood entering the spinning channel. Higher platelet drop per litre processed blood was recorded $(2.2 \pm 0.6 \%)$ when PF 4.5 was used instead of PF 4.0 (2.6 \pm $0.5 \%)$. Reduced platelet loss ultimately led to reduced platelet contamination which improved the quality of the collected cellular component. However, the mechanism on how the decreased centrifugal force affected platelets are not discussed in this study. Hence, centrifugal force must be interlinked to other operating parameters to optimize recovery and purity.

\subsection{Spinning duration}

The spinning duration refers to the required duration for a centrifugal cycle to end, affecting sample recovery, separation efficiency, purity and characteristics of the extracted cells. Longer centrifugation durations slightly increased the platelet recovery and decreased $\mathrm{WBC}$ concentrations in the upper supernatant layer after a first spin step at $100 \times g$ for both 6 min (platelet $=72 \pm 3 \%$; $\mathrm{WBC}=27 \pm 11 \%$ ) and $10 \mathrm{~min}$ (platelet $=79 \pm 8 \%$; WBC $=9 \pm 4 \%$ ) intervals. ${ }^{31}$ Better platelet separation efficiency was also obtained in another study (92\%) by applying an acceleration of $1900 \times g$ for 5 min as compared to $1300 \times g$ for $10 \mathrm{~min} .{ }^{52}$ For fibrin scaffolds, less compaction and thicker filaments were observed in electron micrographs when centrifugation duration used was 20 min rather than 40-60 min (Fig. 1c). ${ }^{37}$ Morphological analysis for fibrin fibre showed that mean fibre diameter decreased after centrifugation from 20 to $60 \mathrm{~min}$ on both horizontal (from $358 \pm 79$ to $205 \pm 57 \mathrm{~nm}, p=0.04$ ) and vertical (from $311 \pm 63$ to $138 \pm 35 \mathrm{~nm}$, $p=0.037$ ) orientation of the rotors used.

In another study however, there is no significant effect in the free haemoglobin ( $\mathrm{fHb}$ ) concentration when the spinning duration was decreased from $7 \mathrm{~min}\left(0.07 \pm 0.04 \mathrm{~g} \mathrm{~L}^{-1}\right)$ to $5 \mathrm{~min}$ $\left(0.07 \pm 0.03 \mathrm{~g} \mathrm{~L}^{-1}\right)$ at both $3000 \times g$ centrifugal force. ${ }^{53}$ The same finding was obtained for the free haemoglobin concentration obtained when centrifugal force used was lower at both $900 \times g$ at 5 and $10 \mathrm{~min}$ centrifugation $\left(61 \mathrm{mg} \mathrm{L}^{-1}\right.$ for control and $79 \mathrm{mg} \mathrm{L}^{-1}$ for centrifuged samples at both 5 and $10 \mathrm{~min}$ ) (Fig. 1d) ${ }^{21}$ Although the difference in duration is small, an increase in $\mathrm{fHb}$ concentration however small, can have a significant effect if it is above analyte specific haemolysis cut-off. $^{53}$ The adverse effects to cells as associated with the 
spinning duration and centrifugal force was also explored and correlated to adenosine triphosphate (ATP) (organic compound that drives many metabolic processes in cells) release with haemolysis. ${ }^{35}$ An increase in the concentration of ATP was observed (from 1.4-4.7 nM) as the centrifugation time increased from 1 to 5 min (Fig. 1c) while varying the applied centrifugal force from $900-16000 \times g .{ }^{35}$ The magnitude of ATP in the packed RBCs obtained using the parameters explored suggests that care must be taken when interpreting ATP transduction data in experiments that utilize centrifugation.

\subsection{Number of spins}

The number of spins pertains to the number of centrifugal cycles in a run. In most runs, centrifugation is repeated up to two cycles and increasing the number of spins can lead to a higher recovery of separated blood component. Processing of $3.5 \mathrm{~mL}$ of blood at $100 \times g$ for $10 \mathrm{~min}$ for the first spin and $400 \times g$ for $10 \mathrm{~min}$ for the second spin while withdrawing $2 / 3$ of the remnant plasma to obtain platelets was performed. ${ }^{40}$ Although a high platelet recovery of $70-80 \%$ was obtained, approximately $20 \%$ of the platelets remained adsorbed in the RBC pellet ${ }^{40}$ after the second spin. Hence, a recorded 5-fold increase in platelet concentration ${ }^{40}$ still requires optimization of the number of spins along with centrifugal force and spinning time to increase the yield and quality of the separated blood components.

The separation of other components found in blood, such as microRNAs, are critical since they serve as biomarkers for tumour diagnosis and prognosis. ${ }^{38}$ The content in representative microRNAs was found to decrease after a two-step centrifugation as compared to a single-step centrifugation. The cell count of miR-BART5, a type of microRNA from a virus involved in a variety of human tumours, in the blood plasma was 40 when a two-step centrifugation was applied compared to 33.5 for a single-step centrifugation process, suggesting that the number of viral microRNAs left in the blood decreased. ${ }^{38}$ The total signal detection rate of microRNAs also decreased (15.3\%) when a two-step centrifugation was applied compared to a single-step centrifugation (21.1\%) (Fig. 1e).$^{38}$ For the evaluation of the purity of detected microRNAs, size distribution of the particles from exosomes - carrier of microRNAs with expected particle size of $30-150 \mathrm{~nm},{ }^{54}$ were assessed by Dynamic Light Scattering (DLS). Particles with mean diameters of $63 \mathrm{~nm}$ present after a one-step centrifugation process were found to increase to $170 \mathrm{~nm}$ after a two-step centrifugation. ${ }^{38}$ However, this two-step protocol did not demonstrate if the extracted microRNAs found after both the first and second steps were similar, and determination of the purity for these biomarkers is yet to be confirmed.

Platelet and leukocyte separation were evaluated after a single and two-step process and it was found that platelet concentration only increased by 1.5 -fold for single-step compared to 4.7 -fold for a two-step process. The leukocyte concentration factor also did not increase for the single-step process but was raised 1.4-fold after the two-step procedure. ${ }^{55}$

\subsection{Conclusions for centrifugal-based apheresis}

Although centrifugation has been the most utilized and established method of separating blood components, intrinsic limitations persist. Centrifugation is labour-intensive and expensive, as the whole apheresis process involves elaborate sample handling and storage most especially in industries that supply blood products where high-capacity centrifuges are utilized. ${ }^{20}$ Variations in separation time, non-reproducibility and low selectivity limit the practical use of traditional centrifugation separation technology. ${ }^{19}$ The main drawback is often related to strong mechanical shear stress induced on the cells, triggering platelet activation and causing haemolysis which can decrease the utility of the extracted blood component. ${ }^{41,56}$ Platelet activation primarily affects the quality of the recovered or extracted blood component by overwhelming the size of the component of interest. Consequently, more anticoagulants are required adding complexity with regards to potential long-term adverse effects including tendency to suffer from bleeding. This technique can also lead to platelet loss of up to $50 \%$ since platelets have a similar density as blood plasma and are therefore difficult to separate from the main blood matrix. ${ }^{25,44,57,58}$ Hence, despite the popularity of centrifugation, platelet activation and haemolysis underpin the search for alternative apheresis technologies.

\section{Membrane-based apheresis}

In membrane-based apheresis, blood components are separated based on their differences in size. Membranes are fabricated to generate pore sizes that will sieve the blood component of interest while retaining other relevant components (schematic diagram on Fig. 2a). ${ }^{3}$ The main application of membrane blood filtration is to remove uremic toxins and excess plasma proteins such as urea, creatinine, immunoglobulins, complement factors and lipoproteins in patients with end-stage renal disease (ERSD) or autoimmune disorders. ${ }^{32-34}$ It can also be used to filter leukocytes (leukodepletion) to avoid transfusion-related diseases. ${ }^{59}$ These applications led to the classification of membrane blood filters as leukodepletion filters, plasma separation membranes and haemodialysis membranes. ${ }^{3,60,61}$ The inherent propensity of the membranes to foul (biofouling), ${ }^{26}$ corresponding to the formation of a cake-layer composed mostly of biological materials, onto the active part of the membrane however represents a major operating challenge.

Properties of the membrane materials can be modified at will to increase biocompatibility and to improve the selectivity and resistance to biofouling. ${ }^{27,57,62}$ Various surface modification techniques are employed such as (i) materials blending, in terms of polymer mixing to form composite materials via physical or noncovalent interaction, (ii) surface grafting, whereby a covalent attachment of functional groups on the membrane surface is performed, and (iii) surface coating, whereby a layer covering the membrane surface is added to enhance biocompatibility. ${ }^{63-65}$ Hence, in this section, potential solutions to address technological gaps in membrane-based apheresis will be discussed including surface modification of 
a

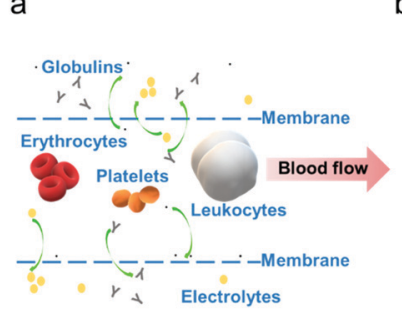

C

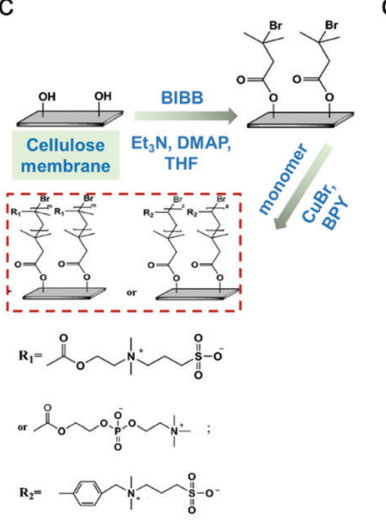

$b$

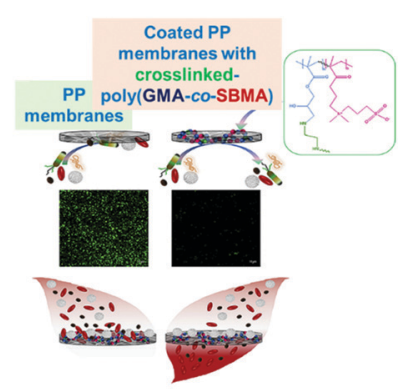

d

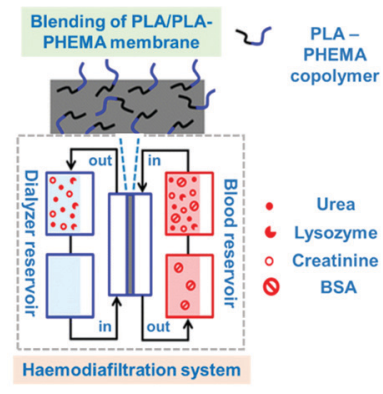

Fig. 2 Membrane-based apheresis. (a) Size-driven separation. Smallersized blood solutes such as electrolytes and globulins (plasma proteins) pass through the membrane sieves whereas larger blood cells such as the erythrocytes, leukocytes and platelets go along the direction of the blood flow. (b) Example of surface modification via coating. Poly(propylene) (PP) membranes were coated with a copolymer (poly(glycidyl methacrylate)co-sulfobetaine methacrylate) (poly(GMA-co-SBMA) with zwitterionic properties to minimize membrane fouling ${ }^{66}$ (c) Example of surface modification via grafting. Cellulose membranes were modified by grafting zwitterionic polymers via surface-initiated atom transfer radical polymerization (ATRP) ${ }^{67}$ (d) Example of surface modification via blending. A block copolymer of poly(lactic acid) (PLA)/poly(hydroxyethylmethacrylate) (PHEMA) was blended with the base material which is poly(lactic acid) to form a more biocompatible membrane. ${ }^{68}$

the common materials used in membrane fabrication for enhanced biocompatibility. Membrane performance before and after surface modification will be evaluated to determine the suitable techniques that can be applied for improved removal efficiencies.

\subsection{Membranes for leukodepletion}

Leukodepletion filters extract white blood cells for the purpose of preparing red blood cells (RBCs) and platelets or removing micro-aggregates, clots, and particle debris from stored or salvaged blood components. ${ }^{60}$ The mechanisms of leukocyte removal could either be driven through cell sieving, based on size or molecular weight cut-off, or cell adhesion, based on the bio-chemical affinity between the membrane and WBCs. ${ }^{60}$ In the 1980s, Asahi and Pall successively proposed non-woven fabric systems for reducing white blood cells. ${ }^{59,69-71}$ Surface grafting of leukocyte filters with positively charged polymers was found to enhance the adsorption of electronegatively charged leukocytes. $^{72}$ In the past 30 years, this concept has been widely used in the development of membrane systems for leukocyte removal processes. ${ }^{69}$ The currently available commercial leukocyte filters which fulfil the criteria of both the European Council (EC) and the American Association of Blood Banks (AABB) for leukoreduced blood components, as well as newly developed leukocyte filters for enhanced leukodepletion are summarized in Table $1 .^{73}$

Current commercial leukodepletion filters have removal efficiencies of up to $99 \%$ and blood components recovered are at around $90 \%$ which satisfies the criteria set by the EC and AABB (Table 1). Membrane surface modification played a key role in enhancing the recovery of leukoreduced blood component yields when these filters are used during leukocyte filtration. Blending, coating or grafting of membrane surfaces affects the surface wettability and charge, thus supporting altered solute/matrix interactions, while also dictating the compatibility of the materials. ${ }^{59}$ Leukocytes were shown to exhibit a greater adherence to wettable surfaces as modelled by observing changes in the free energy of solid surfaces ${ }^{74}$ and more hydrophilic filters, characterized by low contact angles $\left(<90^{\circ}\right),{ }^{75}$ are beneficial to increase the leukocyte removal efficiency.

3.1.1. Poly(ester) leukodepletion filters. Leukodepletion filters are typically made out of nonwoven polyester fibres since it can easily be processed by melt-blowing (one-step fibre fabrication process where fibres are extruded from nozzles by hot, high-velocity air) ${ }^{59}$ without compromising its effectivity to remove leukocytes. ${ }^{69,76-79}$ Polyester is a hydrophobic material therefore surface modification of polyester filters can greatly improve leukocyte depletion efficiency. Also polyester has higher surface energy than other materials for leukocyte filtration like poly(urethane) which makes it more attractive as base materials for leukocyte filters. ${ }^{71}$ Commercial nonwoven polyester fibres for leukodepletion of whole blood can recover up to $90 \%$ of erythrocytes while filtering up to $99.3 \%$ of leukocytes (Table 1, entry 1). ${ }^{69,76-78}$ Aside from erythrocytes, platelet recovery is also a concern during leukofiltration to avoid thrombocytopenia (which may lead to bleeding). Phosphorylcholine (PC), a major phospholipid head group commonly found in outer leaflet of biomembranes, is gaining attention due to its haemocompatibility caused by its zwitterionic structure (hydrophobic head with a hydrophilic tail). ${ }^{80}$ In recent years, a new concept of material design has been proposed that can specifically capture white blood cells, called a zwitterionic bias system. ${ }^{81} \mathrm{~A}$ material must have a combination of zwitterionic groups and charged groups. In an appropriate ratio, it can achieve low platelet activation and a high percentage of leukocyte removal rate. The system was commercialized in 2016 by the start-up company PuriBlood, and clinical testing was introduced. $^{82}$ It has now passed the US FDA and EU CE certification, becoming a new generation of leukocyte filters that can be used to efficiently reduce white blood cells. The internal processing of $500 \mathrm{~mL}$ blood achieves a 99.9\% leukocyte removal in less than $10 \mathrm{~min}$, making it the fastest filtration system.

In one study, ${ }^{83}$ leukocyte depletion increased from around $55 \%$ in unmodified membrane to around $90 \%$ upon coating the 
Table 1 Materials used for leukocyte filtration and surface modification techniques applied for enhanced separation

\begin{tabular}{|c|c|c|c|c|c|c|}
\hline Entry & Material & $\begin{array}{l}\text { Surface- } \\
\text { modified? }\end{array}$ & $\begin{array}{l}\text { Type of surface modification } \\
\text { mainly applied }\end{array}$ & $\begin{array}{l}\text { Blood component } \\
\text { recovered }\end{array}$ & Leukocyte depletion & Recovery \\
\hline 1 & $\begin{array}{l}\text { Nonwoven } \\
\text { polyester fibres }^{69,76-78}\end{array}$ & Yes & $\mathrm{ND}^{a}$ & Erythrocytes & Up to $99.3 \%$ & $>90 \%$ \\
\hline 2 & $\begin{array}{l}\text { Nonwoven } \\
\text { polyester fibres } \\
69,79,83\end{array}$ & Yes & $\begin{array}{l}\text { Coating with phosphorylcholine- } \\
\text { containing polymers }\end{array}$ & Platelets & $>99 \%$ & $93 \%$ \\
\hline 3 & $\begin{array}{l}\text { Microporous } \\
\text { poly(urethane) }\end{array}$ & Yes & Coating with poly(ethylene imine) & $\begin{array}{l}\text { Erythrocytes } \\
\text { Platelets }\end{array}$ & $\begin{array}{l}\text { Up to } 99.6 \% \\
>90 \%\end{array}$ & $\begin{array}{l}>90 \% \\
>90 \%\end{array}$ \\
\hline \multirow[t]{6}{*}{4} & $\begin{array}{l}\text { Microporous } \\
\text { polyurethane }^{85}\end{array}$ & Yes & $\begin{array}{l}\text { Grafting with } \mathrm{Na}_{2} \mathrm{SO}_{3}, \mathrm{H}_{2} \mathrm{SO}_{4} \text {, } \\
\text { glycine, ammonia, } \mathrm{NH}\left(\mathrm{C}_{2} \mathrm{H}_{5}\right)_{2}\end{array}$ & Erythrocytes & $\begin{array}{l}\sim 13 \% \text { permeation } \\
\text { ratio of erythrocytes }\end{array}$ & $<5 \%$ \\
\hline & & & and $\mathrm{NH}_{2} \mathrm{C}_{2} \mathrm{H}_{4} \mathrm{OH}$ & Platelets & $\begin{array}{l}\sim 25 \% \text { permeation } \\
\text { ratio of platelets }\end{array}$ & $<5 \%$ \\
\hline & & & & T-Cells & $\begin{array}{l}\sim 24 \% \text { permeation } \\
\text { ratio of T-cells }\end{array}$ & $\sim 20 \%$ \\
\hline & & & & B-Cells & $\begin{array}{l}\sim 10 \% \text { permeation } \\
\text { ratio of B-cells }\end{array}$ & $\sim 15 \%$ \\
\hline & & & & CD34+ cells & $\begin{array}{l}<1 \% \text { permeation } \\
\text { ratio of CD34+ cells }\end{array}$ & $\sim 70 \%$ \\
\hline & & & & $\begin{array}{l}\text { Mononuclear } \\
\text { cells }\end{array}$ & $\begin{array}{l}\sim 2 \% \text { permeation ratio } \\
\text { of mononuclear cells }\end{array}$ & $<5 \%$ \\
\hline 5 & Poly(propylene) membranes ${ }^{86}$ & Yes & $\begin{array}{l}\text { Grafting with poly(DMAEMA- } \\
\text { co-PEGMA) }\end{array}$ & Erythrocytes & $99.6 \%$ & $98 \%$ \\
\hline 6 & Poly(propylene) membranes ${ }^{66}$ & Yes & $\begin{array}{l}\text { Coating and crosslinking with } \\
\text { poly(GMA-co-SBMA) }\end{array}$ & Erythrocytes & $>99.9 \%$ & $\sim 100 \%$ \\
\hline 7 & Poly(propylene) nonwovens ${ }^{87}$ & Yes & Grafting of "LDV" peptidomimetics & Erythrocytes & $\sim 3.71 \mathrm{log}$ depletion & $\sim 100 \%$ \\
\hline 8 & $\begin{array}{l}\text { Melt-blown poly(butylene } \\
\text { terephthalate) }\end{array}$ & Yes & $\begin{array}{l}\text { Grafting with polar groups } \\
\text { (not disclosed) }\end{array}$ & Erythrocytes & $99.03 \%$ & $95.48 \%$ \\
\hline 9 & $\begin{array}{l}\text { Nonwoven poly(butylene) } \\
\text { terephthalate }^{90}\end{array}$ & Yes & Grafting of poly(vinyl pyrrolidone) & Erythrocytes & $96 \%$ & $92 \%$ \\
\hline 10 & $\begin{array}{l}\text { Nonwoven poly(butylene) } \\
\text { terephthalate }^{91}\end{array}$ & Yes & Coating with hydroxyapatite & Erythrocytes & $98.5 \%$ & $99.5 \%$ \\
\hline 11 & $\begin{array}{l}\text { Electrospun } \\
\text { poly(ethylene-co-vinyl alcohol })^{92}\end{array}$ & No & ND & Erythrocytes & Up to $\sim 99 \%$ & $>90 \%$ \\
\hline
\end{tabular}

polyester fibres with phosphorylcholine-containing polymers such as $\mathrm{MPC}_{37} \mathrm{LMA}_{63}$ (polymer consisting of 2-methacryloyloxyethylmethacrylate (MPC) and lauryl methacrylate (LMA)) (Table 1, entry 2). This result can be attributed to the reorientation of hydrophobic PC head towards the surface of the base material (polyester) minimizing interfacial energy upon blood contact. ${ }^{84}$ As a proof of the reorientation phenomenon, the dynamic contact angle of membranes coated with $\mathrm{MPC}_{37} \mathrm{LMA}_{63}$ also showed that the initial contact angle was high at around $110^{\circ}$ but after a brief immersion in water, the contact angle decreased to around $30^{\circ}$. Upon exposure to an aqueous environment, positively charged PC groups tend to reorient towards the surface minimizing the interaction of the polyester membrane with the blood during coating.

3.1.2. Poly(urethane) leukocyte filters. Other leukocyte filters are made from microporous poly(urethane) (PU) since $\mathrm{PU}$ is also a well-known biocompatible polymer while maintaining its hydrophobicity (Table 1 , entries 3 and 4). ${ }^{69,70,77,78,85}$ Asymmetric poly(urethane) membrane filters with pore sizes decreasing from $65 \mu \mathrm{m}$ to $15 \mu \mathrm{m}$ in the direction of the blood flow led to a moderate removal of leukocytes $(>80 \%)$ achieved at an operating blood flow rate of $\sim 0.2 \mathrm{~mL} \mathrm{~s}^{-1}$. $^{71}$ The leukocytes were only moderately removed since white blood cells such as granulocytes and lymphocytes which comprise about $82 \%$ of leukocytes in the body, have a mean size smaller than $15 \mu \mathrm{m} .{ }^{69}$
Commercial filters have similar performance with nonwoven polyesters when coated with a hydrophilic polymer, poly(ethylene imine) (PEI). ${ }^{69,70,77,78}$ A stable coating with a complete coverage of $0.1 \mathrm{mg} \mathrm{m}^{-2}$ based on ${ }^{14} \mathrm{C}$-labeled PEI mapping of the membrane surface showed that PEI-coated PU leukocyte filters increased the leukocyte depletion efficiency to $>95 \%$ compared with the unmodified filters with efficiency of $\sim 80 \%$. PEI enhanced the performance of PU filters by introducing hydrophilic amine groups on the PU membrane surface. X-Ray photoelectron spectroscopy (XPS) results showed an increase in the nitrogen content from $2.4 \%$ in unmodified membranes to $3.8 \%$ after PEI coating, which verifies that the improved leukocyte removal efficiency is caused by incorporation of a stable PEI coating.

3.1.3. Poly(propylene) leukocyte filters. Poly(propylene) (PP) is also a commonly used material in leukocyte filters (Table 1, entries 5-7 $)^{66,86,87}$ because these highly-porous materials, like poly(sulfone), can be prepared through well-known and controlled processes such as phase inversion, cast film or melt extrusion. ${ }^{88,89}$ Like in other membrane materials, plasma proteins and other blood cells aggravate the tendency of PP membranes to foul reducing the removal efficiency of these filters. A study showed another positive influence of employing a zwitterionic co-polymer in improving the membrane performance and reducing fouling. ${ }^{66}$ Here, coating PP fibres with poly(glycidyl methacrylate-co-sulfobetaine methacrylate) (poly-GMA-co-SBMA) 
(Fig. 2b) presented a high reduction in adsorption of not only leukocytes but also fibrinogen, erythrocytes, thrombocytes and cells from whole blood as compared with the unmodified membranes. Poly-GMA-co-SBMA is immobilized using a crosslinker, ethylenediamine (EDA), and the results were compared before and after adding the crosslinker in the coating bath. The coating density of adding poly-GMA-co-SBMA alone reached to a maximum value of $0.12 \mathrm{mg} \mathrm{cm}^{-2}$ but adding EDA along with the zwitterionic copolymer pushed the coating density to $0.25 \mathrm{mg} \mathrm{cm}^{-2}$. This result shows a direct correlation with the water contact angle wherein membranes have a contact angle of $125^{\circ}$ when poly-GMA-co-SBMA was added alone compared with the unmodified membrane with a contact angle of $135^{\circ}$. There was however limited difference until EDA was added pushing the contact angle to $0^{\circ}$ given that the concentration of poly-GMA-co-SBMA was $1 \mathrm{mg} \mathrm{mL}{ }^{-1}$. The drastic change from being a highly hydrophobic to superhydrophilic polymer led to a leukocyte removal efficiency of $>99 \%$ without altering the erythrocyte concentration in the permeate compared with unmodified membranes with only $\sim 50 \%$ retention.

3.1.4. Poly(butylene terephthalate) leukocyte filters. A surfacegrafted commercial leukocyte filter non-woven poly(butylene terephthalate) (PBT-NW) fabric was found to improve the leukocyte retention and erythrocyte recovery (Table 2 , entry 9$)^{90}$ by grafting with poly(vinyl pyrrolidone) (PVP) using oxygen plasma priming treatments. Upon the evaluation of the membrane surface wettability through the measurement of the critical wetting surface tension (CWST) parameter, CWST increased from 44.2 to $>92.5 \mathrm{mN} \mathrm{m}^{-1}$ upon plasma priming. CWST of haemocompatible materials were previously reported to require to be of at least $78 \mathrm{mN} \mathrm{m}^{-1}$ in order to see if liquid applied wetted the pores or remained as a droplet on the membrane surface. ${ }^{83}$ The leukocyte retention and erythrocyte recovery were increased from $\sim 85 \%$ to $96 \%$ and from $\sim 83 \%$ to $92 \%$, respectively, using these grafted PBT non-woven fabrics. Aside from grafting PVP, leukocyte filter performance was also improved upon addition of hydroxyapatite, deposited onto the surface of PBT nonwoven fibres. ${ }^{91}$ The water contact angles were measured for both pristine PBT-NW and HA-coated membranes leading to a decrease from $124^{\circ}$ (pristine) to $100^{\circ}$ (HA-coated) after deposition. The improved hydrophilicity generated by the HA addition increased the removal efficiency of leukocytes from $\sim 85 \%$ to $98.5 \%$, and that of erythrocytes from $\sim 95 \%$ to $99.5 \%$. A challenge remains related to the long-term stability of HA, and potential leaching of the loosely polymerized materials into the blood stream. The release of such additives could yield potential pathogenic effects when blood is returned to the body, which shall be carefully investigated in future studies.

3.1.5. Poly(ethylene-co-vinyl alcohol) leukocyte filters. Electrospun poly(ethylene-co-vinyl alcohol) membranes have the exceptional advantage of being spun using nontoxic solvent such as rubbing alcohol. ${ }^{92}$ These membranes are prepared with a range of nanofibre diameters, and it was reported that leukocyte adhesion was identified across the thickness of samples (Table 1, entry 11). ${ }^{92}$ A histological examination showed that the fibre diameters, ranging from 0.7 to $3.0 \mu \mathrm{m}$, however played a significant role since very few cells were found to adhere onto membrane materials made from $0.7 \mu \mathrm{m}$ fibres, while a larger density of leukocytes was present across the membranes with larger fibres and thus pore size distributions.

\subsection{Membranes for toxin removal}

Aside from leukocytes with sizes ranging from 6-10 $\mu \mathrm{m},{ }^{69}$ other blood components such as plasma proteins and uremic toxins are removed to achieve haemostasis. Plasma separators are used for the purpose of collecting plasma proteins such as immunoglobulins, albumin and lipopolysaccharides, which are known precursors to endotoxins and cholesterols including low-density lipoprotein (LDL) and high-density lipoprotein (HDL) and to replace unhealthy blood plasma with a fresh and healthy one in patients with autoimmune diseases. ${ }^{9}$ Plasma components have pore sizes of $>100 \mathrm{~nm}$ hence the pore size distribution range of membrane plasma separators is typically narrower and finer than that of leukodepletion filters, and in the microfiltration (MF) range of 0.2 to $0.8 \mu \mathrm{m} .{ }^{93}$ Haemodialysis membranes, on the other hand, are primarily employed for the removal of low molecular weight uremic toxins $(<500 \mathrm{Da})$ which could be of the size of $<10 \mathrm{~nm} .{ }^{94,95}$ Higher molecular weight toxins $>60000$ Da with a size range $>10 \mathrm{~nm}$ but $<100 \mathrm{~nm}$ are removed by haemofiltration membranes, the separation mechanism follows the principle of convection and not diffusion, as with haemodialyzers., ${ }^{3,96}$ Currently available membranes for toxin removal are presented in Tables 2 and 3.

Plasma separators and haemodialyzers could be made out of cellulose or synthetic polymers such as poly(sulfone), poly(ethylene), poly(lactic acid), to name a few (Table 3). Like in leukodepletion filters, these materials can be modified through the previously specified techniques for a more efficient separation of plasma proteins and uremic toxins. The use of zwitterionic polymers, ${ }^{67}$ vitamin $\mathrm{E}^{97}$ and chitosan ${ }^{98}$ are only some of the added materials developed for a more enhanced performance and haemocompatibility. Interestingly, the use of nanoparticles such as silicon dioxide, ${ }^{99}$ ferric oxide ${ }^{100}$ and multi-walled carbon nanotubes ${ }^{101}$ are also explored as anti-fouling agents.

3.2.1. Cellulosic membranes for toxin removal. Cellulose membranes (CM) have been frequently used in blood purification therapies since production cost is inexpensive and these membranes are relatively thin compared to others facilitating easier component transport ${ }^{102}$ (Table 2, entry 2). However, a membrane with too many hydrophilic groups may lead to leukopenia or reduced number of WBCs. ${ }^{103}$ Meanwhile, as the degree of substitution from the hydrophilic to less hydrophilic moieties, as in cellulose acetate, increases, there is also a higher propensity for protein fouling. ${ }^{80}$ Hence, surface-initiated atom transfer radical polymerization (ATRP) was used to graft zwitterionic polymers on the membrane surface to balance the number of hydrophilic and hydrophobic moieties in cellulose membranes. ${ }^{67}$ Surface-initiated ATRP involves esterification of hydroxyl groups using the initiator, 2-bromoisobutyryl bromide (BIBB) to form initiator-functionalized cellulose membranes (CM-Br) (Fig. 2c). Then, CM-Br sheets will be reacted with copper(I) bromide (CuBr), zwitterionic monomer and 2,2'-bipyridine (BPY) 







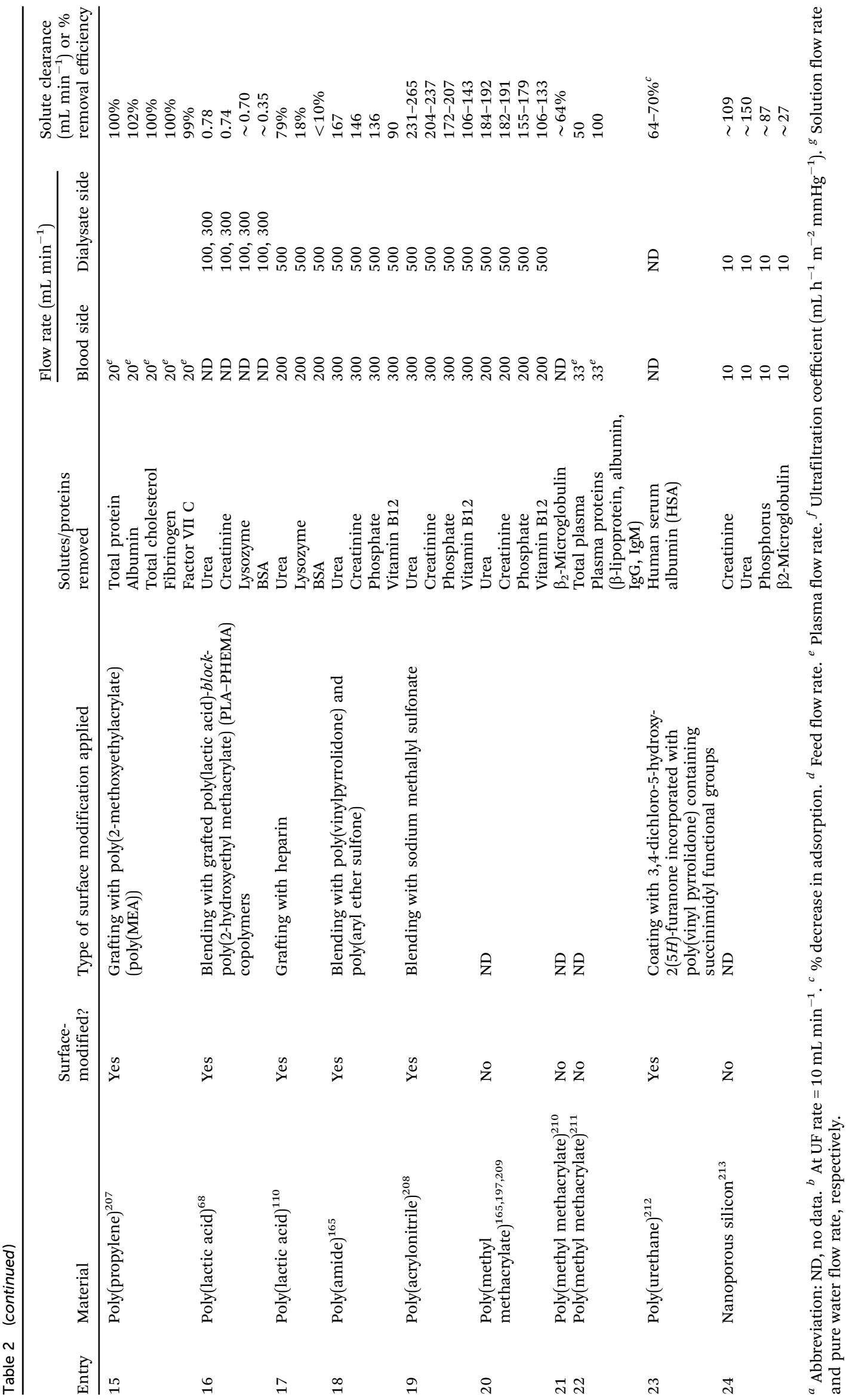


to form the zwitterionic polymer-grafted CM (Fig. 2c). Interestingly, by grafting one poly(phosphobetaine) and two poly(sulfobetaine) compounds using ATRP, the contact angle changed from $\sim 47^{\circ}$ in the unmodified membrane to $\sim 34-20^{\circ}$ in modified membranes. This result was due to the formation of a hydration layer via electrostatic interactions in addition to the hydrogen bonding. ${ }^{104}$ Although it was shown that there was a decreased protein adsorption from $1.8 \mu \mathrm{g} \mathrm{cm} \mathrm{cm}^{-2}$ in pristine membranes to around $1 \mu \mathrm{g} \mathrm{cm}^{-2}$ in modified membranes and reduced platelet adhesion based on the morphological analysis, the number of leukocytes was not measured in the pristine and modified membranes for this study. The problem on leukopenia is left unanswered and warrants further investigation.

Cellulose acetate (CA) membranes are also used in blood purification to address the problem with the number of $-\mathrm{OH}$ group in cellulose membranes that would lead to leukopenia (Table 2, entry 3). ${ }^{103}$ Here, hydroxyls of the unmodified cellulose were substituted by acetate radicals to minimize hydrophilicity. Although CA membranes were linked to reduced complement activation due to the presence of negative charges on the surface that can adsorb the activated cationic complement peptide, ${ }^{105}$ there are still a few concerns such as limited mechanical strength and shelf-life. ${ }^{106,107}$ To address these concerns, a novel method of covalently adding inorganic nanoparticles such as $\mathrm{SiO}_{2}$ with mechanical and thermal stability properties to CA membranes was explored. ${ }^{99}$ By combining the phase inversion and sol-gel techniques, a $\mathrm{CA} / \mathrm{SiO}_{2}$ monophasic hybrid membrane was formed. After optimizing the amount of silica added, it was found out that when $5 \mathrm{wt} \%$ silica was added to CA membrane, there was no significant change in contact angle but when $11 \mathrm{wt} \%$ and $18 \mathrm{wt} \%$ silica were added to the CA membrane respectively, the contact angle decreased from $\sim 40^{\circ}$ to around $14^{\circ}$ and $22^{\circ}$ respectively. The surface roughness will influence the hydrophilicity but when the average roughness of the hybrid membrane was obtained through atomic force microscopy, it was found that there is not much difference in the nano $(1.0-2.5 \mathrm{~nm})$ and the micro $(6.0-7.3 \mathrm{~nm})$ range for the CA membranes with 5,11 and $18 \mathrm{wt} \%$ silica added thus surface roughness did not affect the hydrophilicity in this case. With regards to the anti-fouling ability, it was shown that urea is fully permeated with $\%$ rejection of $\sim 0.3 \%$ for $11-18 \%$ silica-CA hybrid membranes from $2 \%$ in unmodified CA membranes whereas BSA is fully rejected in both modified and modified CA at $99 \%$ rejection. Hence, this membrane is selective in filtering urea and retaining BSA and plasma proteins with similar size which is highly desired during haemodialysis.

3.2.2. Synthetic membranes for toxin removal. Synthetic membranes were found to generally yield wider pore size distributions and greater biocompatibility than cellulosic membranes by slowing down leukocyte adhesion ${ }^{108,109}$ and therefore supporting faster filtration rates of $>100 \mathrm{~mL} \mathrm{~min}^{-1}$. As opposed to cellulosic membranes, synthetic polymeric membranes are hydrophobic and will certainly prevent leukocyte adhesion although these materials will promote protein adsorption and will foul easily. Hence, when separating proteins, it is better to have a hydrophilic additive for enhanced filtration flux. 
3.2.2.1. Poly(sulfone) and poly(ether sulfone) membranes. Poly(sulfone) (PSf) and poly(ether sulfone) (PES) are the primary materials used in fabricating haemodialysis membranes and plasma filters however, high membrane hydrophobicity causing low removal efficiency of middle-molecular weight toxins such as $\beta_{2}$-microglobulin is the current trade-off in using these membrane materials. ${ }^{101}$ The incorporation of metal oxides is also explored not only in cellulose acetate membranes ${ }^{99}$ but also in synthetic polymers such as poly(sulfone). Iron(III) oxide $\left(\mathrm{Fe}_{2} \mathrm{O}_{3}\right)$ is blended with poly(sulfone) membranes because aside from its hydrophilicity and nontoxicity, its nanostructure facilitates better water porosity at minimal operating pressure (Table 2, entry 6). ${ }^{100}$ Although the exact mechanism of how it became a good liquid transport medium is not explained, true enough, $\mathrm{PSf} / \mathrm{Fe}_{2} \mathrm{O}_{3}$ membranes exhibited more finger-like structures and thinner skin layer than PSf membrane alone. The pore size distribution also shifted to larger mean sizes due to the greater freedom in movement of $\mathrm{Fe}_{2} \mathrm{O}_{3}$ near the membranemoisture interface. The contact angle values decreased from $67^{\circ}$ to $55^{\circ}$ and water porosity increased from $43 \%$ to $67 \%$ leading to lesser human serum albumin (HSA) adsorption from $8.23 \mu \mathrm{g} \mathrm{cm} \mathrm{cm}^{-2}$ to $6.68 \mu \mathrm{g} \mathrm{cm} \mathrm{cm}^{-2}$ and higher BSA rejection from $91 \%$ to $98 \%$ in $\mathrm{PSf} / \mathrm{Fe}_{2} \mathrm{O}_{3}$ membranes. The clearances for the relevant haemodialysis solutes - urea and lysozyme were $75.1 \%$ (from $52.3 \%$ urea clearance) and $35.6 \%$ respectively. Lysozyme clearance was better at $35.6 \%$ compared to other studies $-18 \%$ using heparin-immobilized poly(lactic acid) (PLA) membrane ${ }^{110}$ and $28 \%$ multi-walled carbon nanotube (MWCNT)-incorporated PES membrane. ${ }^{111}$ Lysozyme has about the same molecular weight as the common middle-molecular weight $\beta_{2}$-microglobulin $(\sim 15 \mathrm{kDa})$ but the size of lysozyme is $9 \mathrm{~nm}$ in length and $1.8 \mathrm{~nm}$ in diameter. ${ }^{112} \beta_{2}$-Microglobulin is $<200 \mathrm{~nm}$ in length and $\sim 10 \mathrm{~nm}$ wide. ${ }^{113}$ Better representation molecule for middle-molecular weight toxins must be considered in future studies.

Other surface modifications were also applied to PSf membranes such as coating PSf membranes with vitamin $\mathrm{E}$ to capture reactive oxygen species in blood that are activated during blood-membrane contact. ${ }^{97}$ This is not the first time that vitamin E-coated PSf membranes were reported in the literature. ${ }^{114-116}$ However, this is the first study to demonstrate the mass-transfer characteristic of vitamin E-coated PSf membranes. Filtration experiments on aqueous test solutions of creatinine, vitamin $\mathrm{B}_{12}$, chymotrypsin and albumin were done at flow rates of $100 \mathrm{~mL} \min ^{-1}$ on the blood side and $10 \mathrm{~mL} \mathrm{~min}^{-1}$ on the dialysate side. Upon coating PSf membranes with $\alpha$-tocopherol - the active form of vitamin $\mathrm{E}$, it was discovered that there is no significant difference in the efficiency of small solute removal such as creatinine and vitamin B12 against the uncoated membranes $(\sim 100 \%)$. However, significant changes were observed when larger solutes such as chymotrypsin and albumin were filtered. The removal efficiency of chymotrypsin decreased from $\sim 86 \%$ in uncoated membranes to $\sim 82 \%$ in coated membranes during the first $30 \mathrm{~min}$ of filtration. Same changes were observed when albumin was filtered wherein the removal efficiency decreased to $\sim 2 \%$ from $\sim 4 \%$ during the first 30 min of filtration. Morphological analysis presented a wedge-shaped structure on the cross-section wherein large pores are filled with white drops that can be related to the successful coating of vitamin E. This result shows that addition of vitamin $\mathrm{E}$ influenced the mass transfer properties of the PSf membranes and can make the filter more selective towards small solutes and more discriminative towards middle to high molecular weight proteins such as albumin which is necessary for homeostasis.

Polymer blends were used to generate asymmetric membranes from poly(ether sulfone) (PES) and a co-polymer, SlipSkin ${ }^{\mathrm{TM}}$ (SS) with randomly arranged monomeric moieties of hydrophilic NVP ( $N$-vinylpyrrolidone) and hydrophobic BMA ( $N$-butylmethacrylate) (Table 2, entry 10). ${ }^{117}$ Morphological analyses showed the presence of macrovoids in both PES-SS and PES-PVP membranes while no macrovoids were present across the PES-SS membranes. Enhanced long-term filtration fluxes for both PES-SS (1.3-fold increase) and PES-PVP (5-fold increase) were achieved compared to commercial F8HPS membranes, measured after $24 \mathrm{~h}$ of filtration. Interestingly, although the PES-SS membranes exhibited more macrovoids than the PES-PVP membranes, the relative flux for the PES-PVP was higher than that of the PES-SS (2.6-fold higher), which was attributed to leaching of PVP over time thus leading to unstable pore size and surface energy distributions within the materials. ATR-IR spectra confirmed this hypothesis where large variations in the intensity of the carbonyl peaks at 1680-1700 $\mathrm{cm}^{-1}$ for PES-PVP membranes were found between the reference sample and after $24 \mathrm{~h}$ of filtration. With regards to the anti-fouling ability of the PES-SS membranes, removal of both soluble (creatinine) and protein-bound uremic toxins (hippuric acid, HA and indoxyl sulfate, IS) were examined. The PES-SS membranes has $\sim 89 \%$ better creatinine removal efficiency than commercially available low-flux F8HPS (Fresenius) fibres, which was linked to the presence of a hydrophilic NVP ( $N$-vinylpyrrolidone) block within the SS polymer, into the selective layer and pore surface of the PES-SS hollow fibres. These NVP were anchored by the hydrophobic BMA ( $N$-butylmethacrylate) block of the SS into the membrane polymer matrix leading to less interaction between the membrane and the soluble solute. ${ }^{118,119}$ Interestingly, there is a low removal efficiency for hippuric acid which is only $\sim 59 \%$ which could be related to the fact that there is a higher protein interaction and adsorption of HA on the surface of the commercial membrane as compared to the PES-SS membrane. Also, HA binds to plasma proteins at a lower degree $(\sim 30 \%)$ as compared to IS ( $\sim 90 \%)$. Hence, no significant difference was recorded for the IS removal for both the commercial and PES-SS membranes.

Adding hydrophilic polymers has been a common surface modification technique for hydrophobic membranes to minimize problems in fouling that will lead to cascade of reactions such as platelet activation and complement system activation. However, hydrophilic polymers tend to swell in water which is eluded in dialysis process as it affects the removal efficiency of membranes. ${ }^{111}$ Hence, exploration of blending synthetic polymer membranes with nanomaterials that can serve as inorganic fillers to avoid swelling is a growing trend in membrane technology. ${ }^{101}$ 
Carbon nanotubes (CNT) have been used as nanofillers for their nanoscale dimensions, which can offer high membrane specific surface area for interactions with contaminants or resources. In addition, both hydrophobic and hydrophilic blood components can interact with this material via $\pi-\pi$ stacking and hydrogen bonding with oxygen-rich species $(-\mathrm{COOH}$ and $-\mathrm{OH})$ in its chemical structure. ${ }^{111}$ In the first study that fabricated multiwalled carbon nanotube (MWCNT)/PES membranes, poly(vinyl pyrrolidone) (PVP) was the other additive that was incorporated to avoid MWCNT aggregation while reducing the elution of PVP during filtration (Table 2, entry 11). ${ }^{111}$ Urea, creatinine and lysozyme were filtered at a rate of $125 \mathrm{~mL} \mathrm{~min}^{-1}$ at the simulated blood solution side and $50 \mathrm{~mL} \mathrm{~min}^{-1}$ at the pure water solution side which gave higher removal efficiencies of $56.3 \%$ for urea, $55.1 \%$ for creatinine and $27.9 \%$ for lysozyme than the unmodified membranes. These values are relatively low compared to the performance of other mixed matrix membranes (MMMs) that incorporated inorganic nanofillers (Table 2, entries 3 and 6) and also filtered urea ${ }^{99}(\sim 97 \%)$ and lysozyme ${ }^{100}(\sim 36 \%)$. Possible reasons could be the tendency of PVP to leach after prolonged hours of filtration and the inadequate amount of added MWCNT (0.05-0.2 g) to sustain PVP in the matrix. Hence, another MWCNT/ PES MMM membrane was proposed which used MWCNT-grafted poly(citric acid) (PCA) as another additive instead of PVP. ${ }^{101}$ Hydrophilic poly(citric acid) was grafted with MWCNTs since MWCNTs are more well-dispersed when grafted with polymers and other large organic molecules than grafting with acid alone. ${ }^{120}$ Addition of solid oxidized (O)-MWCNTs in the PES dope solution increased the solution viscosity from 5121 to $7797 \mathrm{mPa}$. However, when the PCA- $g$-MWCNTs were added, a reduction of viscosity from $7797 \mathrm{mPa}$ s to $6564 \mathrm{mPa} s$ was recorded. This result is an implication of the inverse relationship between the viscosity and the average size or molecular weight distribution of MWCNT. An increase in the molecular weight of the PCA- $g$-MWCNTs led to greater shear rate thus lesser solution viscosity. As a result, larger voids were formed leading to a lower BSA absorption of $65.3 \%$ than the unmodified membrane.

3.2.3. Poly(lactic acid) membranes. Despite the biocompatibility of the current synthetic polymer haemodialyzers such as PSf and PES, waste disposal issues arise given that these membranes are for single-use only. ${ }^{121,122}$ Hence, aside from biocompatibility, there has also been an increasing research on materials that are both biocompatible and biodegradable. ${ }^{123}$ Poly(lactic acid) (PLA), a biocompatible polymer, has been used as the base membrane in some haemodialyzers because of its biodegradability however, its hydrophobicity makes it prone to fouling like PSf and PES membranes. ${ }^{124}$ Hence, PLA grafted with an amphiphilic block co-polymer, poly(2-hydroxyethyl methacrylate) (PHEMA) was being developed for better durability and antifouling capacity (Table 2 , entry 16). ${ }^{68}$ Grafting of PHEMA with PLA was done via reversible addition-fragmentation (RAFT) polymerization from aminolyzed PLA. Briefly, aminolysis reaction of PLA with ethylenediamine (EDA) formed PLA-EDA which was used to synthesize PLA-CDP from 4-cyano4-(dodecylsulfanylthiocarbonyl)sulfanylpentanoic acid (CDP) via esterification/amination between the hydroxyl $(-\mathrm{OH}) / \mathrm{amino}$
$\left(-\mathrm{NH}_{2}\right)$ groups of PLA-EDA and the carboxyl $(-\mathrm{COOH})$ groups of CDP. PLA-CDP was used as a macromolecular chain transfer agent during RAFT polymerization. HEMA and the initiator, azobisisobutyronitrile (AIBN) was added to PLA-CDP under $70{ }^{\circ} \mathrm{C}$ with constant stirring at an inert atmosphere forming the block copolymer PLA-PHEMA. Ultimately, PLA-PHEMA was added to PLA to form a more hydrophilic PLA/PLA-PHEMA membranes. Water contact angle measurements were obtained, and it was observed that the contact angles decreased from $75.8^{\circ}$ in pristine membranes to around $71.4^{\circ}-60.5^{\circ}$ in PLA/PLAPHEMA membranes confirming increase in hydrophilicity. When clearance for urea, creatinine, lysozyme and BSA were compared (Fig. 2d), it was observed that there is no significant difference in the clearances of small solutes such as urea $\left(0.78 \mathrm{~mL} \mathrm{~min}^{-1}\right)$ and creatinine $\left(0.74 \mathrm{~mL} \mathrm{~min}^{-1}\right)$ for both the pristine and modified membranes. However, when larger solutes such as lysozyme and BSA were compared, it was observed that lysozyme clearance increased from $\sim 0.15 \mathrm{~mL} \mathrm{~min}^{-1}$ in pristine membranes to $\sim 0.7 \mathrm{~mL} \mathrm{~min}^{-1}$ in PLA/PLA-PHEMA membranes and BSA clearance was also increased from $\sim 0.05 \mathrm{~mL} \mathrm{~min}^{-1}$ to $\sim 0.35 \mathrm{~mL} \mathrm{~min}^{-1}$. Hence, PLA/PLA-PHEMA membranes can be developed further for removal of middle molecular weight toxins in blood plasma.

3.2.4. Poly(ether imide) membranes. Most of the studies mentioned focused on the biofouling problem of most haemodialyzers and plasma filters but only few studies actually measured platelet and complement system activation on these membranes and the impact of membrane surface modification on blood coagulation proteins. Studies on how surface modification affect these remaining gaps were summarized in Table 3. Activated partial thromboplastin time (APTT), prothrombin time (PT) and plasma re-calcification time (PRT) were measured via coagulation analyzers and assays to evaluate platelet and complement system activation. APTT, PT and PRT are general testing procedures to evaluate coagulation abnormalities in the blood coagulation pathways. APTT is for the measurement of coagulation abnormalities in the intrinsic pathway composed of clotting factors such as factor IX, X and XI and is activated by collagen whereas PT is for the measurement of coagulation abnormalities in the extrinsic pathway - pathway activated by trauma in the vascular system, platelets, exposed endothelium or chemical which is composed of clotting factors such as factor VII and III. ${ }^{125}$ Generally, when these parameters increase, it means that the interaction between the blood and membrane surface took longer for platelets to be activated subsequently triggering a cascade of reaction in the intrinsic pathway. Previous studies showed that the use of inorganic nanofillers such as MWCNTs and metal oxides improved the antifouling capacity of membranes ${ }^{99-101}$ but a study confirmed the haemocompatibility of a biocompatible polymer, poly(ether imide) (PEI) by measuring APTT, PT and PRT of pristine PEI and graphene oxide incorporated PVP-PEI membranes. Graphene oxide is a two-dimensional material that is an oxidized form of graphene. Graphene consists of a single layer of carbon arranged in $\mathrm{sp}^{2}$ bonded aromatic structure. ${ }^{126}$ Graphene oxide (GO) is now used as an inorganic nanofiller for its ultrathin 
structure and high mechanical strength contributing to high throughput in membranes. ${ }^{126}$ Since 2D materials have limited biocompatibility, haemocompatibility testing was done in this study to ensure minimized platelet activation (Table 3, entry 2). APTT, PT and PRT increased from $32 \mathrm{~s}, 15 \mathrm{~s}$ and $325 \mathrm{~s}$ in unmodified membranes to $75 \mathrm{~s}, 18 \mathrm{~s}$ and $675 \mathrm{~s}$ in modified membranes, respectively. The results show that by adding GO to the PEI/PVP membrane, there is a decreased interaction between the hydrophobic plasma proteins and blood since GO facilitates better incorporation of PVP with PEI and GO itself has hydrophilic moieties that will repel these proteins. ${ }^{111}$

\subsection{Conclusions for membrane-based apheresis}

Membrane apheresis is one of the most promising blood apheresis technology for its scalability and versatility. From an operational point of view, the focus of membrane apheresis has been directed towards minimizing surface fouling by applying such material modification methods to improve performance and conserve hospital resources by reducing procedure duration. ${ }^{25}$ This strategy is implemented by ensuring that an increased amount of blood toxins is removed to prevent compromising of the quality and purity of the extracted cells and of the filtered blood that will be returned to the patient at the end of the apheresis procedure. However, only few studies elaborated on the causes for these materials' enhanced performance, in terms of chemical or surface/interfacial energy changes. ${ }^{74,84}$ A drive towards improved selectivity in blood apheresis is also required due to the large range and complexity of blood components exhibiting wide size distributions and biochemistries. Efficient speciation of certain components, which are the cause of diseases or of industrial value, may be currently hampered due to the presence of other similarly sized materials. One such example is related to the extraction of IgG and the competitive transfer of albumin during membrane apheresis. ${ }^{61,127}$ In addition, testing the haemocompatibility of the added material to ensure applicability on extracorporeal blood purification is not yet performed systematically, which should become a good practice with materials scientists to develop relevant materials solutions. $^{128,129}$

\section{Adsorption-based apheresis}

Sorbent apheresis technologies are developed to typically remove unwanted blood components using separation mechanisms beyond diffusion and convection. ${ }^{4}$ Specifically, selective sorbent materials for haemoperfusion have been developed since the 1970's for treatment of drug poisoning, to treat immunological diseases and remove uremic toxins. ${ }^{4,130}$ Some common uremic toxins that must be separated from blood are urea, creatinine and bilirubin. Urea and creatinine are toxic by-products of muscle and protein metabolism and high levels of these toxins implies impaired kidney function. ${ }^{131}$ Meanwhile, bilirubin is a by-product of red blood cell metabolism and high bilirubin levels indicates impaired liver function. ${ }^{132}$ Removal of bilirubin is necessary as this toxic metabolite can cause jaundice or condition where skin appears yellow. ${ }^{132}$ Separation of these toxins using these sorbent technologies is promising since, as opposed to centrifugation or membrane separation, only solutes of interest are retained through physical or chemical adsorption processes (schematic diagram on Fig. 3a). ${ }^{133}$

Leaching or release of sorbents over time however, remains a major challenge most especially if the material is not biocompatible, causing adverse effects to the patient such as chills, fever, cutaneous rush, thrombocytopenia and leukopenia. ${ }^{4}$ Strategies to minimize such adverse reactions or immunological responses from the body such as containing the adsorbents within specifically designed cartridges or modules are critical to allow for proper and safe operation and direct contact with the blood. ${ }^{134}$ Two solutions have emerged involving (i) separation of the plasma from the blood cells prior to

a

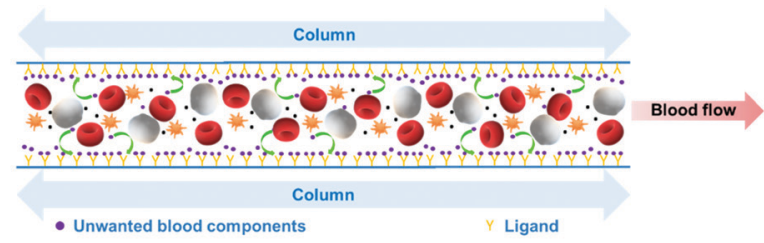

b
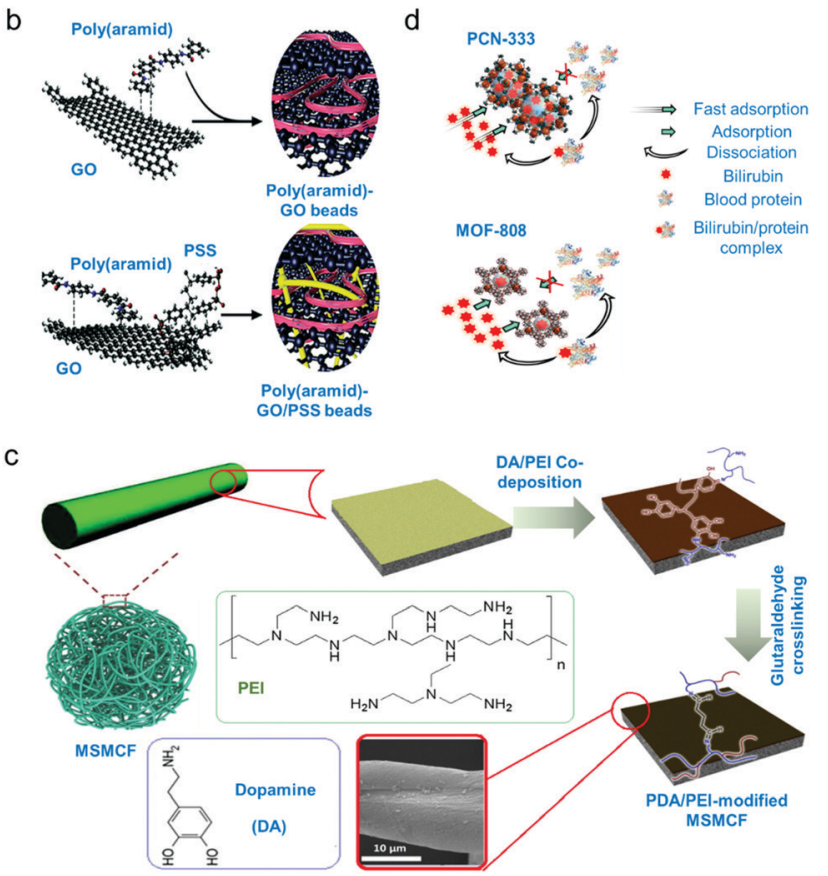

Fig. 3 Adsorption-based apheresis. (a) Affinity-based separation. A ligand or sorbent attached to the column surface attracts the blood component of interest by affinity due to charge or shape complementarity. (b) An example of sorbent for direct haemoperfusion. Poly(aramid)-GO/PSS gel beads were crosslinked via $\pi-\pi$ interactions. ${ }^{136}$ (c) An example of sorbent for plasma perfusion. Biocompatibility of sorbents is increased by coating with a hydrophilic polymer. Micrometre-size magnetic carbon fibres (MSMCF) are functionalized with a more stable poly(dopamine)/poly(ethylene imine) (PDA/PEI) coating by crosslinking the magnetically separated MSMCF/PDA/PEI mixture using glutaraldehyde to form PDA/ PEI-modified MSMCF. ${ }^{137}$ (d) Metal-organic frameworks (MOFs) as adsorbent. Mechanism of capture for two cage-based MOFs were shown. High specificity toward bilirubin is demonstrated by dissociation of blood protein from the bilirubin/protein complex after capture. ${ }^{138}$ 
Table 4 Sorbents used for haemoperfusion and the corresponding modifications for enhanced adsorption capacity

\begin{tabular}{|c|c|c|c|c|c|c|c|c|}
\hline Entry & Sorbent & $\begin{array}{l}\text { Sorbent } \\
\text { modification? }\end{array}$ & $\begin{array}{l}\text { Type of sorbent } \\
\text { modification }\end{array}$ & $\begin{array}{l}\text { Pore size } \\
(\mathrm{nm})\end{array}$ & $\begin{array}{l}\text { BET surface } \\
\text { area } \\
\left(\mathrm{m}^{2} \mathrm{~g}^{-1}\right)\end{array}$ & $\begin{array}{l}\text { Adsorbed } \\
\text { blood } \\
\text { component }\end{array}$ & $\begin{array}{l}\text { Adsorption } \\
\text { capacity (per } \\
\text { gram or \%) }\end{array}$ & Application \\
\hline 1 & $\begin{array}{l}\text { Carbon-based } \\
\text { sorbent } \\
\text { materials }^{140}\end{array}$ & No & $\mathrm{ND}^{a}$ & $0.8-1$ and 5 & 1250 & $\begin{array}{l}\text { Creatinine } \\
\text { Indoxyl sulfate } \\
\text { (IS) } \\
\text { Hippuric acid } \\
\text { (HA) } \\
\text { Interleukin-6 } \\
\text { (IL-6) } \\
\text { Interleukin-8 } \\
\text { (IL-8) }\end{array}$ & $\begin{array}{l}\sim 14 \mathrm{mg} \\
\sim 3.7 \mathrm{mg} \\
\sim 13 \mathrm{mg} \\
\sim 33 \mathrm{ng} \\
\sim 80 \mathrm{ng}\end{array}$ & $\begin{array}{l}\text { Direct } \\
\text { haemoperfusion }\end{array}$ \\
\hline 2 & $\begin{array}{l}\text { Magnetic } \\
\text { carbon fibre }\end{array}$ & Yes & $\begin{array}{l}\text { Coated with } \\
\text { dopamine- } \\
\text { poly(ethylene)imine } \\
\text { (PEI) }\end{array}$ & 35 and 5200 & 146 & Bilirubin & $335 \mathrm{mg}$ & $\begin{array}{l}\text { Plasma } \\
\text { perfusion }\end{array}$ \\
\hline 3 & $\begin{array}{l}\text { Nanostructured } \\
\text { silica } \\
\text { materials }\end{array}$ & Yes & $\begin{array}{l}\text { Functionalization } \\
\text { with 1-hydroxy-2- } \\
\text { pyridinone }(1,2- \\
\text { HOPO-SAMMS })\end{array}$ & $\sim 6$ & 900 & $\begin{array}{l}\text { Free and } \\
\text { chelated } \\
\text { gadolinium } \\
\text { (gadopentetate } \\
\text { dimeglumine } \\
\text { and } \\
\text { gadodiamide) }\end{array}$ & $\begin{array}{l}99 \% \text { in } 1 \mathrm{~min} \\
\text { (free); } 95 \% \text { in } \\
30 \mathrm{~min} \\
\text { (gadodiamide) }\end{array}$ & $\begin{array}{l}\text { Direct and } \\
\text { plasma } \\
\text { perfusion }\end{array}$ \\
\hline 4 & $\begin{array}{l}\text { Cage-based } \\
\text { metal organic } \\
\text { frameworks } \\
(\text { MOFs) }\end{array}$ & No & ND & $\begin{array}{l}1.84-5.5 \\
\text { (cage size) }\end{array}$ & $2060-4000$ & Bilirubin & $\sim 1003 \mathrm{mg}$ & $\begin{array}{l}\text { Plasma } \\
\text { perfusion }\end{array}$ \\
\hline 5 & $\begin{array}{l}\text { Kevlar-based } \\
\text { composite gel } \\
\text { beads }{ }^{142}\end{array}$ & Yes & $\begin{array}{l}\text { Crosslinking of } \\
\text { sodium } p \text { - } \\
\text { styrenesulfonate } \\
\text { (SS) onto Kevlar- } \\
\text { graphene oxide (GO) } \\
\text { interface }\end{array}$ & $\begin{array}{l}50000 \text { (gel } \\
\text { shell) }\end{array}$ & ND & $\begin{array}{l}\text { Creatinine } \\
\text { Bilirubin }\end{array}$ & $\begin{array}{l}97 \% \\
79 \%\end{array}$ & $\begin{array}{l}\text { Direct } \\
\text { haemoperfusion }\end{array}$ \\
\hline 6 & $\begin{array}{l}\text { Non-ionic } \\
\text { microporous } \\
\text { poly(styrene } \\
\text { adsorbent) }^{156}\end{array}$ & No & ND & 4.8 & 795 & Bilirubin & $50 \%$ & $\begin{array}{l}\text { Plasma } \\
\text { perfusion }\end{array}$ \\
\hline 7 & $\begin{array}{l}\text { Heparin- } \\
\text { mimetic gel } \\
\text { beads }^{145}\end{array}$ & Yes & $\begin{array}{l}\text { Crosslinking of } \\
\text { carrageenan and } \\
\text { poly(acrylic acid) } \\
\text { networks }\end{array}$ & $\begin{array}{l}32000- \\
22000\end{array}$ & ND & $\begin{array}{l}\mathrm{Cu}^{2+} \\
\text { Creatinine } \\
\text { Low density } \\
\text { lipoprotein } \\
\text { (LDL) } \\
\text { Bilirubin }\end{array}$ & $\begin{array}{l}560 \mathrm{mg} \\
15 \mathrm{mg} \\
18 \mathrm{mg}\end{array}$ & $\begin{array}{l}\text { Direct } \\
\text { haemoperfusion }\end{array}$ \\
\hline 8 & $\begin{array}{l}\text { Molecularly- } \\
\text { imprinted } \\
\text { biomimetic } \\
\text { adsorbent }^{157}\end{array}$ & No & ND & 3.6 & 210 & $\begin{array}{l}\alpha \text {-Amanitin } \\
\beta \text {-Amanitin }\end{array}$ & $\begin{array}{l}\sim 91-96 \% \\
\sim 90-92 \%\end{array}$ & $\begin{array}{l}\text { Plasma } \\
\text { perfusion }\end{array}$ \\
\hline 9 & $\begin{array}{l}\text { CCL-25 } \\
\text { columns }^{146}\end{array}$ & No & ND & ND & ND & $\begin{array}{l}\text { CCR-9 expres- } \\
\text { sing cells }\end{array}$ & $98 \%$ & $\begin{array}{l}\text { Direct } \\
\text { haemoperfusion } \\
\text { (leukoreduction) }\end{array}$ \\
\hline 10 & $\begin{array}{l}\text { Solid phase } \\
\text { extraction }^{158} \text { adsorbent }^{158}\end{array}$ & No & ND & 2.75 & 183 & $\begin{array}{l}\text { Ampicillin } \\
\text { sodium }\end{array}$ & $13.5 \mathrm{mg}$ & $\begin{array}{l}\text { Plasma } \\
\text { perfusion }\end{array}$ \\
\hline
\end{tabular}

circulation through the sorbent bed or (ii) the coating of the sorbent materials with a secondary bio- or haemocompatible material. ${ }^{135}$ The applicability and throughput of these strategies will be discussed in this section.

\subsection{Sorbents for direct haemoperfusion}

In direct perfusion columns, adsorbent cartridges are used to be in direct contact with blood within the column housing. ${ }^{139}$ In this apheresis mode, the micron-sized sorbent particles provide fast and efficient removal capacity of all the toxins they are designed to capture. However, direct haemoperfusion does not offer control over the fluid balance and the ability to remove other contaminants simultaneously, such as urea. ${ }^{140}$

4.1.1. Carbon-based sorbent materials. Semi-continuous carbon-based sorbent materials with tailored dual pore size distributions were designed to ensure that both small solutes such as urea and larger protein-bound uremic toxins, $\beta_{2}$-microglobulin and cytokines could be simultaneously adsorbed (Table 4, entry 1). ${ }^{140}$ CMK-3 type carbon adsorbents were synthesized to exhibit both micropores $(<2 \mathrm{~nm})$ and mesopores $(2-50 \mathrm{~nm})$. The sorbent produced via a pyrolysis process consisted of a set of parallel rods hexagonally packed and 
interconnected with thin carbon strands. The pore size distribution within the rods ranged between 0.8 and $1 \mathrm{~nm}$, which was effective in capturing small water-soluble molecules and protein-bound toxins (PBTs). The space between the rods generated a well-defined and easily tuneable mesoporous matrix with narrow pores, on the order of $5 \mathrm{~nm}$, which enabled the removal of low molecular weight molecules $(<500 \mathrm{Da}$, $<10 \mathrm{~nm})^{94,95}$ and cytokines without hindering diffusion across the micropores. A wide range of solutes was demonstrated, ranging from creatinine, $\beta_{2}$-microglobulin, PBTs like hippuric acid ( $48 \%$ bound to HSA) and indoxyl sulphate ( $98 \%$ bound to HSA), as well as the removal of two cytokines, IL-6 and IL-8. The performance of the CMK-3 adsorbents was compared with two commercially available carbon-based sorbents (Norit A Supra, $3 \mathrm{~nm}$ and Takeda $5 \mathrm{~A}, 0.6 \mathrm{~nm}$ ). For creatinine, the CMK-3 and Norit A Supra exhibited superior adsorption capacity than the Takeda $5 \mathrm{~A}$, which was attributed to their higher specific surface areas (SSA) between 1250 and $1700 \mathrm{~m}^{2} \mathrm{~g}^{-1}$ for the CMK-3 and Norit A, respectively, compared to only $560 \mathrm{~m}^{2} \mathrm{~g}^{-1}$ for the Takeda resins. The SSA normalized adsorption capacities of CMK-3 was higher compared to the Norit A Supra, at $14 \mathrm{mg}$ and $11 \mathrm{mg} / 1000 \mathrm{~m}^{2}$ for CMK-3 and Norit A, respectively. The capture of PBUTs was similar and the CMK-3 offered a slightly higher specific SSA adsorption capacity for IS $\left(\sim 2.9 \mathrm{mg} / 1000 \mathrm{~m}^{2} v s . \sim 2.2 \mathrm{mg} / 1000 \mathrm{~m}^{2}\right)$ and $\mathrm{HA}(10.1 \mathrm{mg} /$ $1000 \mathrm{~m}^{2}$ vs. $9.8 \mathrm{mg} / 1000 \mathrm{~m}^{2}$ ) than Norit A. The scalability of the process with CMK-3 was discussed and it was shown that in this scenario, only 128 and $22 \mathrm{~g}$ of the adsorbent were required to remove either creatinine or PBUTs. As a benchmark, a kidney patient generates daily creatinine production on the order of $\sim 1800 \mathrm{mg}$, while the mean daily excretion of IS and HA is on the order of $69 \mathrm{mg}$ and $270 \mathrm{mg}$, respectively. ${ }^{141}$ The capture of medium molecular weight molecules and cytokine clearance with CMK-3 was demonstrated with up to $42 \%$ of IL-6 and $68 \%$ of $\beta_{2}$-microglobulin removal in the same experimental conditions, whereas Norit A $\left(0 \mathrm{ng} \mathrm{g}^{-1}\right)$ and Takeda $\left(0 \mathrm{ng} \mathrm{g}^{-1}\right)$ performed extremely poor for cytokine removal. The Takeda resin however, was able to remove $22 \%$ of the $\beta_{2}$-microglobulin.

4.1.2. Poly(aramid)-based composite gel beads. Direct haemoperfusion was performed with poly(aramid)-based composite gel beads (Table 4 , entry 5 and Fig. 3 b). ${ }^{142}$ Poly(aramid) nanofibres were utilized as a scaffold and combined to graphene oxide (GO). ${ }^{136}$ First, poly(aramid) nanofibre - GO beads were produced by liquid-liquid phase separation. Then, $\pi-\pi$ interaction of sodium- $p$-styrene sulfonate (SS) onto the poly(aramid)GO interface was initiated by ammonium persulphate (APS) to form composite poly(aramid)-GO-poly(styrene sulfonate) (PSS) beads with an interfacial cross-linked structure. The composite K-GO/PSS beads exhibiting a dual-network structure and a heparinmimicking gel structure were obtained and haemoperfusion experiments showed an increase in capture capacity by $97 \%$ $\left(\sim 350 \mu \mathrm{g} \mathrm{mL} \mathrm{m}^{-1}\right.$ beads $)$ for creatinine and $79 \%(\sim 5610 \mu \mathrm{g} \mathrm{mL}$ beads) for bilirubin compared to poly(aramid) alone $\left(\sim 110 \mu \mathrm{g} \mathrm{mL} \mathrm{L}^{-1}\right.$ beads and $\sim 2810 \mu \mathrm{g} \mathrm{mL} \mathrm{m}^{-1}$ beads for removal of creatinine and bilirubin, respectively). The haemocompatibility study was however performed with platelet-poor plasma as the control, reducing the relevance of the work. The indicators of platelet activation for APTT, TT and PRT increased from $\sim 44 \mathrm{~s}, 21 \mathrm{~s}$ and $255 \mathrm{~s}$ for the control materials to $\sim 66.4 \mathrm{~s}, 38.8 \mathrm{~s}$ and $14400 \mathrm{~s}$, for the modified samples, and this trend indicated that platelet activation was inhibited. PTT remained at similar concentration for both the control and the modified beads at $\sim 12 \mathrm{~s}$, which indicated that extrinsic coagulation pathways were not activated. Observing the serum concentrations of the anaphylatoxins C3a and C5a as indicators for complement activation, the serum C3a concentration only increased from $1750 \mathrm{ng} \mathrm{mL}{ }^{-1}$ to $1900 \mathrm{ng} \mathrm{mL}^{-1}$ while the serum C5a concentration only decreased from $38 \mathrm{ng} \mathrm{mL}^{-1}$ to $32 \mathrm{ng} \mathrm{mL}^{-1}$ which is not clinically relevant. Since C5a is a more potent chemoattractant than C3a, K-GO/PSS did not induce inflammatory response from these mediators upon contact of blood to the beads which confirms its haemocompatibility.

4.1.3. Heparin-mimicking adsorbents. Natural-based adsorbents extracted from raw materials such as zeolites (aluminosilicate) and porous carbons (cellulose-derived organic polymers prepared by controlled thermal oxidation) exhibit some level of an inherent biocompatibility. ${ }^{143,144}$ However, the relatively poor mechanical strength and low surface functional group contents available for surface modification remain a challenge towards implementing such sorbents. Heparin-mimicking carrageenan and poly(acrylic acid) (PAA) cross-linked networks were synthesized via combination of phase inversion of carrageenan and post-crosslinking of AA. The beads with dual-network structures have improved mechanical properties and controlled swelling ratios (Table 4, entry 7) ${ }^{145}$ The average pore size post modification decreased from $32 \mu \mathrm{m}$ to $22 \mu \mathrm{m}$. Adsorption capacities improved from $150 \mathrm{mg} \mathrm{g}^{-1}$ to $560 \mathrm{mg} \mathrm{g}^{-1}$ for $\mathrm{Cu}^{2+}, 6 \mathrm{mg} \mathrm{g}^{-1}$ to $15 \mathrm{mg} \mathrm{g}^{-1}$ for creatinine, $1.5 \mathrm{mg} \mathrm{g}^{-1}$ to $18 \mathrm{mg} \mathrm{g}^{-1}$ for LDL and from $100 \mathrm{mg} \mathrm{g}^{-1}$ to $228 \mathrm{mg} \mathrm{g}^{-1}$ for bilirubin compared to the carrageenan reference. The improvement in the adsorption capacities can be associated with the presence of a large density of negative and oxygen-containing functional groups, which enabled strong interactions with the positively-charged probe molecules. Haemocompatibility tests and indicators of antithrombogenicity such as APTT, PT and TT all increased from $44.5 \mathrm{~s}$ to $413.9 \mathrm{~s}, 13.3 \mathrm{~s}$ to $51.6 \mathrm{~s}$ and $18.1 \mathrm{~s}$ to $60.1 \mathrm{~s}$, respectively supporting that intrinsic, extrinsic and common coagulation pathways were activated at a very minimal rate. Serum plasma concentrations of anaphylatoxins C3a and C5a, were also observed and decreased from 3250 to $\sim 2900 \mathrm{ng} \mathrm{mL}^{-1}$ and 80 to $38 \mathrm{ng} \mathrm{mL}^{-1}$, respectively. This trend demonstrated that no trigger of the complement system occurred, which should limit risks for allergic reactions and inflammatory responses.

4.1.4. Biotinylated columns. CCL-25 columns were also developed for direct haemoperfusion to remove over-expressed CCR9 cells in patients with inflammatory bowel disease (IBD) ${ }^{146}$ Compared to commercially available Adacolumn ${ }^{\circledR}$ made up of cellulose acetate beads, this column offered more specific adsorption mechanisms for certain types of leukocyte and CCR9expressing cells thanks to the interactions between chemokine and the corresponding cell surface receptors. Streptavidinconjugated sepharose beads were selected as carrier matrices for their high affinity with biotinylated chemokine, CCL-25 
$\left(K_{\mathrm{d}} 4 \times 10^{-14}\right)$ and such biotinylated columns were found to be highly selective towards CCR9-expressing cells. In fact, $98 \%$ of the CCR9-expressing cells in healthy donors were reduced leading to depletion of at least $100 \times 10^{6}$ cells.

\subsection{Sorbents for plasma perfusion}

Plasma perfusion adsorbents consist of a base material coated with an active functional ligand layer for selective coordination of plasma components. ${ }^{139}$ During plasma perfusion, the extracted plasma from a plasma separator is flushed through a column containing the adsorbents to prevent damage to the cellular components, known to reduce the adsorption efficiency of the process significantly. ${ }^{139}$

4.2.1. Magnetic carbon fibres. The possibility of magnetic materials as blood-cleansing adsorbent for non-invasive treatments of various diseases, such as sepsis, was demonstrated by tagging particular etiological components, corresponding to disease-causing agents, prior to letting them interact with a magnetic material. ${ }^{147}$ Carbon fibres are thread-like carbon materials with excellent mechanical performance and multiple functional properties including low-levels of magnetic properties. ${ }^{148}$ Such materials may contain micro- and mesopores or be modified through specific activation-etching schemes to increase the pore density. ${ }^{149}$ Micrometre-sized magnetic carbon fibre coated with poly(dopamine)/poly(ethylene imine) complexes (PDA/PEI-modified MSMCF) were developed for the adsorption of bilirubin (Fig. 3c). ${ }^{137}$ Since the surface of the carbon fibres is not natively active, incorporating other polymers may be challenging. ${ }^{150}$ The introduction of a poly(dopamine) (PDA) coating via hydrophilic crosslinking with glutaraldehyde, led to instabilities caused by the inherently strong interactions of the catechol chemical structure with the dopamine monomer. As a result, the modified magnetic carbon fibres yielded relatively comparable total bilirubin clearance (14-66\% within 2 h equilibrium adsorption) with HSA-immobilized magnetic beads (31\% within $2 \mathrm{~h})^{151}$ and lysine-attached aluminium oxide-silica membrane (35\% within $4 \mathrm{~h}$ ). ${ }^{152}$ An increased PRT from $282 \mathrm{~s}$ to $318 \mathrm{~s}$ and a decreased serum concentration of anaphylatoxins $\mathrm{C} 3 \mathrm{a}$ and $\mathrm{C} 5 \mathrm{a}$ from $45 \mathrm{ng} \mathrm{mL}^{-1}$ to $25 \mathrm{ng} \mathrm{mL}^{-1}$ and from $1.9 \mathrm{ng} \mathrm{mL} \mathrm{m}^{-1}$ to $1.0 \mathrm{ng} \mathrm{mL^{-1 }}$, respectively were recorded for MSMCF/PDA/PEI compared to MSMCF alone showing that this sorbent is haemocompatible.

4.2.2. Nanostructured materials as adsorbents. Nanostructured materials offer very high surface area and chemically selective functionality which allows for tailoring of the 3D architecture, pore size, and interfacial chemistry. ${ }^{153}$ Self-assembled monolayers on mesoporous silica supports (SAMMS ${ }^{\mathrm{TM}}$ ) were used as sorbents for both free and chelated gadolinium (Gd) in the treatment of patients with chronic kidney disease and nephrogenic systemic fibrosis (NSF) - a condition wherein the skin of extremities tightens and swells accompanied by weakness of muscles limiting the ability to move. ${ }^{138}$ These SAMMS ${ }^{\mathrm{TM}}$ were functionalized with 1-hydroxy-2-pyridinone (HOPO) using 3-aminopropyltrimethoxysilane as coupling agent. ${ }^{154}$ HOPO-complexing agents were selected with $\mathrm{SAMMS}^{\mathrm{TM}}$ for their ability to sequester heavy metals in nuclear waste. ${ }^{155}$ Upon application in haemoperfusion, HOPO-functionalized SAMMS ${ }^{\mathrm{TM}}$ were able to adsorb 99\% of free Gd within $1 \mathrm{~min}$ and 95\% of chelated Gd within $30 \mathrm{~min}$. An advantage of this approach is that the continued use of Gd-contrast magnetic resonance imaging (MRI) can be performed to avoid NSF in renal patients. Cagebased metal organic frameworks (MOFs) also showed a recordhigh selective adsorption of bilirubin $\left(\sim 1000 \mathrm{mg} \mathrm{g}^{-1}\right)$ which is over 69 times higher than clinically approved activated charcoal materials (Fig. 3d). ${ }^{133}$ This adsorption capacity was attributed to the multiple $\pi-\pi$ interactions with parallel-displaced configurations formed between the aromatic rings of bilirubin and ligand of the MOF which is 4,4,4-s-triazine-2,4,6-triyl-tribenzoic acid $\left(\mathrm{H}_{3}\right.$ TATB). Therefore, such nanostructured materials represent clear avenues to yield enhanced removal rates and selectivity towards specific blood components.

4.2.3. Non-ionic microporous polymer adsorbents. A nonionic microporous poly(styrene) adsorbent, SZ-9, was also developed to avoid the activation and coagulation cascade caused by the strong basic functional groups within commercial adsorbent columns (BL-300) made from a porous anion exchange resin coated with hydrophilic 2-hydroxyethylmethacrylate copolymer. ${ }^{156}$ Gas adsorption analysis of the SZ-9 and BL-300 adsorbents to determine the pore size distribution showed that the SZ-9 adsorbents were made up of highly porous, uniformly shaped spherical beads with a Lorentzian pore size distribution between 10 and $50 \mathrm{~nm}$, and a mean value at $\sim 20 \mathrm{~nm}$. However, the BL-300 adsorbents are composed of irregularly shaped but narrower pores, ranging from 1 to $10 \mathrm{~nm}$, for a mean value of $3 \mathrm{~nm}$. The specific surface area of the SZ-9 was found to be higher $\left(794.9 \mathrm{~m}^{2} \mathrm{~g}^{-1}\right)$ than BL-300 (592.4 $\left.\mathrm{m}^{2} \mathrm{~g}^{-1}\right)$ with the average pore diameter $(4.8 \mathrm{~nm})$ found to be larger than that of BL-300 (3 nm). The dynamic adsorption data acquired for the total bilirubin, direct bilirubin, indirect bilirubin and total bile acid in the blood plasma on the adsorbents, showed that the SZ-9 performed better than the BL-300 and exhibited a slightly higher adsorption efficiency, ranging from $47 \%$ in BL-300 to $50 \%$ in SZ-9, for bilirubin. SZ-9 also exhibited negligible percentage of haemolysis $(-0.4 \%)$ compared with BL-300 which was reported at $\sim 11 \%$. Hence, these resins appear safe for application in the treatment of fulminant hepatitis and postoperative hepatitis using haemoperfusion. ${ }^{139}$

4.2.4. Molecularly imprinted adsorbents. Molecularly imprinting is also another material processing technology used to synthesize biomimetic adsorbents. $\alpha$ - and $\beta$-amanitin, two major types of mushroom poisons, were removed separately from blood using molecular imprinted materials. ${ }^{157}$ The specific surface areas obtained using Brunauer-Emmett-Teller (BET) analysis for the molecularly imprinted vinylated silica microspheres were $0.021 \mathrm{~m}^{2} \mathrm{~g}^{-1}$ for the MIP compared to $0.017 \mathrm{~m}^{2} \mathrm{~g}^{-1}$ for the non-imprinted polymer, which were similar. However, high selectivity factors were calculated for the $\alpha$ - (6.53) and $\beta$ - (6.21) amanitin which could be attributed to the difference in Trp-Cys cross-bridge located at the convex domain of these bicyclic octapeptide, which is the natural pattern of the amanitin molecule. Adsorption capacities of $92-95 \%$ for $\alpha$-amanitin and $90-92 \%$ for $\beta$-amanitin were obtained compared 
to $60-70 \%$ and $56-57 \%$ only for their corresponding nonimprinted polymer, respectively. Molecularly imprinted amino-functionalized silica particles were also used as solid phase extraction adsorbents to remove ampicillin sodium from blood samples (Table 4, entry 10). ${ }^{158}$ Compared with the amanitin-specific vinylated silica particles, specific surface area of ampicillin sodium-specific silica particles obtained was higher at $183 \mathrm{~m}^{2} \mathrm{~g}^{-1}$ than the non-imprinted reference material $\left(173 \mathrm{~m}^{2} \mathrm{~g}^{-1}\right)$. The adsorption capacity of MIP is $\sim 71 \%$ more than the NIP. Hence, molecularly imprinted materials are good adsorbents for separating stereo-selective or regio-selective molecules. Developments of such materials and integration into meso-porous scaffolds offer great promises towards flow-through adsorbents design.

\subsection{Conclusions for adsorbent-based apheresis}

Adsorbent-based apheresis is a technique that use affinitybased separation enabling specific molecule to capture through electrostatic interactions, hydrogen bonding or shape complementarity. Although adsorption is very efficient and promising overall selectivity, the process may still be improved, and novel surface chemistries must be developed to enable more selective capture mechanisms. The design of specific micro or nano pore distributions may also support performance, but pre-treatment is nevertheless required prior to operation to facilitate the adsorption process. Carbon-based sorbent materials are largely non-selective but represent an excellent scaffold material and their microstructures and pores may be tuned to allow for separation based on size.

The haemocompatibility and toxicity of the ligand materials used to build chemical adsorbents remain a challenge by hindering direct blood contact and adding costly cartridge designs. The grafting of antibodies was discontinued for instance due to strong side effects triggering platelet activation. ${ }^{159}$ Hence, patient safety and disease indications should still be carefully monitored prior to selecting a base material for the sorbent.

\section{Microfluidic-based apheresis}

Microfluidic-based separation technologies emerged during the late 1970's and gained interest for their ability to separate very efficiently minute blood volumes of approximately up to one nanolitres with flow rates of up to $1 \mu \mathrm{L} \min ^{-1.5,28,160}$ Microfluidics is mainly applied during collection of blood components for novel therapies as part of clinical trials and for isolation of blood components for disease prognosis. ${ }^{161}$ The main speciation mechanisms rely on size and deformability of blood cells, and can be controlled using the fluidic properties, flow rate and channel geometry (schematic diagram in Fig. 4a). ${ }^{5}$

Separation by microfluidics technologies can be classified as active, passive or combined as in the case of label-free cell sorting mechanisms. ${ }^{28}$ In active approaches, external force fields are applied to effect particle motion during blood fractionation. ${ }^{162}$ Active separation techniques can be based on magnetophoresis, whereby particles move in a magnetic field, acoustophoresis, if particles migrate with soundwaves, and dielectrophoresis, upon non-uniform electric field application. ${ }^{28}$ Passive techniques do not require external forces to drive the separation and rely on the interaction of phenomena including diffusion, hydrodynamic forces such as inertial and Dean's forces, and the intrinsic physical properties of the cells including size and deformability. ${ }^{28,161,163}$

The fabrication material employed by most current microfluidic devices developed for diagnostic apheresis is poly(dimethylsiloxane) or PDMS - a transparent and inert polymer that is inexpensive. ${ }^{164}$ It is commonly used for purposes of blood component separation because aside from it is nontoxic, it entails very simple device fabrication. ${ }^{164}$ Other materials that can be used are glass and various thermoplastics, which can

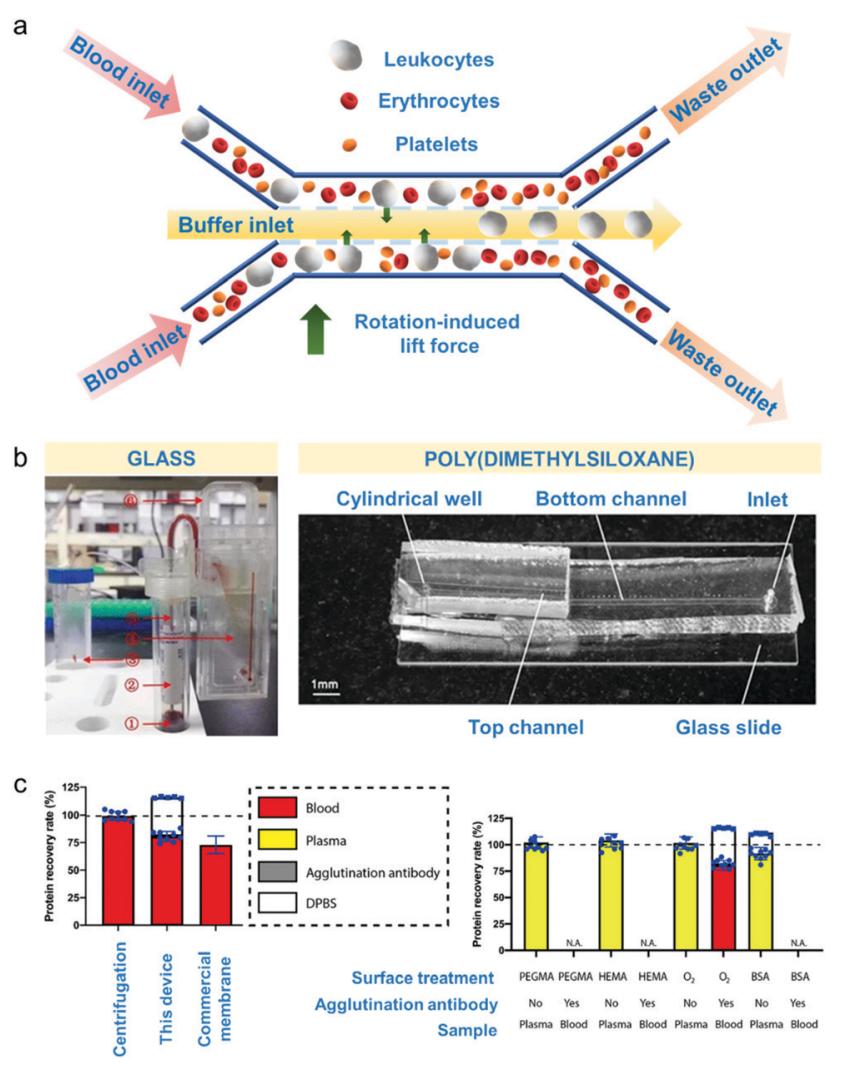

Fig. 4 Microfluidic-based apheresis. (a) An example of microfluidic separation. ${ }^{165}$ As blood sample is introduced, the plasma (liquid component) exerts rotation-induced lift force on the sphere-like blood components such as leukocytes, erythrocytes and platelets which causes size-based lateral migration. (b) Materials used for device fabrication of apheresis chips. ${ }^{145,166}$ Poly(dimethylsiloxane) or PDMS is the most commonly used but glass is also employed for blood component separation. (c) Comparison of microfluidic apheresis device with already established apheresis techniques (centrifugation and membrane filtration). Total plasma protein recovery (left) is significantly higher than the protein recovery obtained after membrane filtration considering the amount of agglutination antibody protein incorporated with the device Effects of surface treatments such as treating with poly(ethylene glycol)methyl ether methacrylate (PEGMA) solution, hydroxyethylmethacrylate (HEMA) solution, bovine serum albumin (BSA) solution and oxygen plasma (right) show that BSA treatment gave the highest \% recovery rate considering also the amount of agglutination antibody incorporated with the device. 
also be biocompatible but in the prototyping stages fabrication process fabrication can be more complex and have higher infrastructure demands than making PDMS devices by soft lithography. ${ }^{164}$ Hence, this section will focus on device design principles aside from the fabrication materials used and the surface modification applied towards these materials to increase separation efficiency, throughput and recovery (Table 5).

\subsection{Microfluidic devices for leukapheresis}

Current leukoreduction retains leukocytes via a membrane filtration process while allowing other blood components to pass with the flow through the pores prior to returning to the body. Membrane fouling, platelet activation and complement system activation are key challenges of membrane apheresis. In order to address this limitation, a high-throughput passive microfluidic device to remove leukocytes from platelet-rich plasma (PRP) in a continuous flow regime using controlled incremental filtration (CIF) was developed (Table 5, entry 1). ${ }^{167}$ Here, leukocytes were separated from platelets within the PRP by progressively syphoning clarified PRP away from the concentrated leukocyte flow stream. Poly(dimethylsiloxane) (PDMS) was the material used to fabricate the device replicas for separation runs but these replicas were treated with $1 \%(\mathrm{w} / \mathrm{v})$ aqueous solution of methyl-end capped trimethoxy poly(ethylene glycol) silane (mPEG-silane) to reduce protein adsorption and fouling. ${ }^{168}$ Uncoated PDMS can lead to higher fibrinogen adsorption causing more immediate platelet activation. ${ }^{169}$ Using this device, $99.9 \%$ of leukocytes were removed based on the filtrate PRP while recovering $>80 \%$ of the original platelets at volumetric throughputs of $\sim 1 \mathrm{~mL} \mathrm{~min}^{-1}$. These results suggest that CIF approaches will enable users in many fields to exploit microfluidic phenomena, even at throughputs nearing the flow rates used for continuous flow centrifugation $\left(\sim 50 \mathrm{~mL} \mathrm{~min}^{-1}\right)$.

Integrated micro-fabricated filters were used for the separation of leukocytes (Table 5, entries 2 and 3) based on deformability. ${ }^{170,171}$ Initially, microfilters with gap sizes gradually decreasing from 15 to $3 \mu \mathrm{m}$ were used. ${ }^{170}$ The distribution of captured cells was analysed for different flow rates, cell sizes and cell deformability. Changes in fluidic behaviour with variation in flow rates allowed for the collection of leukocytes of different sizes at different flow rates. At high sample flow rate

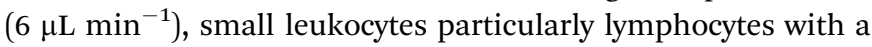
size of $7 \mu \mathrm{m}$ permeated across the smallest microfilter gap size of $3 \mu \mathrm{m}$, whereas at lower flow rates $\left(1.5 \mu \mathrm{L} \mathrm{min}{ }^{-1}\right)$, lymphocytes were captured in a $6 \mu \mathrm{m}$ microfilter gap size. Although this system offers a low sample throughput compared to the CIF device, ${ }^{167}$ it does offer a high separation efficiency for WBCs $(100 \%)$ with regard to other blood components such as cancer cells and RBCs.

Another filter-integrated device based on diffusion in a continuous flow was developed, ${ }^{171}$ where the geometry of the diffuser was optimized to ensure that the fluid distributes equally across the individual sieve elements. When a flared geometry was used, a separation efficiency of $>97 \%$ was achieved for leukocytes at a higher sample throughput $\left(5 \mu \mathrm{L} \min ^{-1}\right)$ than previously reported for microfluidic devices $\left(1.5 \mu \mathrm{L} \mathrm{min}{ }^{-1}\right)$.
Hence, the optimised geometry supported greater throughput. The device is versatile since it can also be used for plasma fractionation by reducing the height of filter elements from $2.5 \mu \mathrm{m}$ to $<0.5 \mu \mathrm{m}$. Leukocyte and erythrocyte separation however, depends mainly on pressure gradient across filter elements which is a function of operating flow rate and in this case, higher flow rates will permit stronger interaction between the leukocytes and erythrocytes with the filter elements than lower flow rates.

\subsection{Microfluidic devices for erythrocytapheresis}

Erythrocytes may also be separated from whole blood for blood donation or red cell exchange. ${ }^{41}$ Two types of passive microfluidic device that are based on crossflow filtration were fabricated to separate RBCs from whole blood (Table 5, entries 4 and 5). ${ }^{172}$ Microstructures including as micro-pillar arrays and micro-weirs were used in a filtration device. PDMS was still the main fabrication material of choice but in the first chip (Table 5, entry 4), ${ }^{173}$ glass is compounded with PDMS over a silicon substrate. Considering the microstructures incorporated with the device, the rationale for the material of choice could be the fact that glass compensates for the elasticity of PDMS which may affect accuracy of the fabricated channel dimensions. ${ }^{174}$ In terms of the mode of membrane filtration, cross flow filtration was used as opposed to dead end filtration to ensure large particles remain suspended while the small particles permeate through the filter; in dead-end filtration large particles may clog or jam the pores. ${ }^{175,176}$ Consequently, by employing the design principle and fabrication material, separation efficiencies were greater than $95 \%$ and $27 \%$ for RBC and WBC, respectively.

Besides incorporating filters within the microfluidic device, a passive microfluidic chip driven by the inertial migration effect was also developed to separate and enrich leukocytes from whole blood. ${ }^{177}$ The chip design incorporated 10 switchback curve channels bridged by straight channels for inducing inertial migration effects to concentrate the blood cells while the curved channels were integrated for inducing Dean flow - a secondary cross-sectional force field characterized by the two counter-rotating vortices perpendicular to the direction of the flow for further separation of cells based on their sizes. ${ }^{178}$ This configuration led to the very high erythrocyte separation efficiency with almost no erythrocyte loss $(\sim 100 \%$ capture efficiency) while still recovering $\sim 93.2 \%$ of the leukocytes from whole blood.

\subsection{Microfluidic devices for circulating tumour cell (CTC) isolation}

Circulating tumour cells (CTCs) are cancer cells that migrate away from primary site and are distributed throughout the body using the bloodstream. ${ }^{145}$ CTCs are considered attractive biomarkers for cancer diagnosis/prognosis as sampling blood may be less invasive than taking tumour biopsies. ${ }^{17}$ However, their very low concentration (1-100 CTCs per $\mathrm{mL}$ of blood) makes their detection challenging. ${ }^{179}$ So far, CTCs can be separated based on their physical properties such as size and deformability since CTCs have comparable sizes as other blood cell 


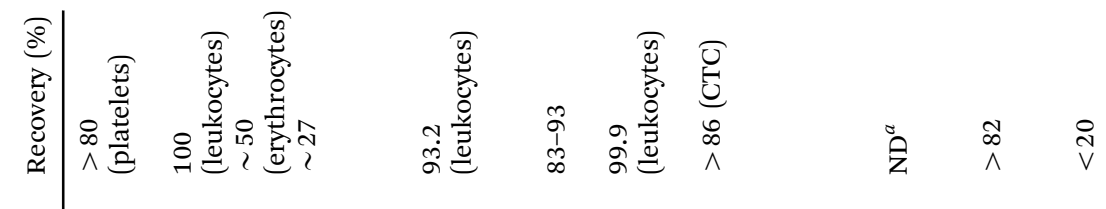

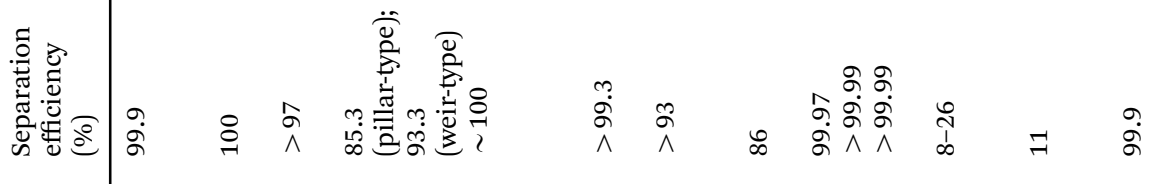



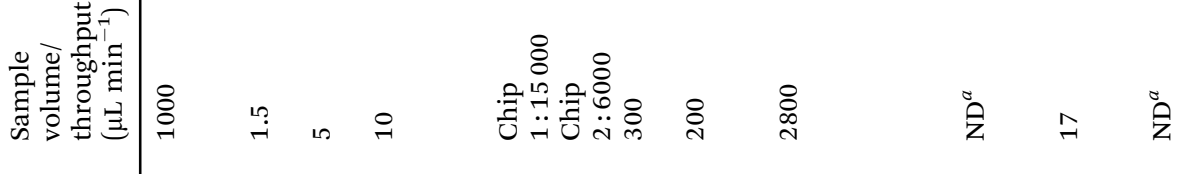

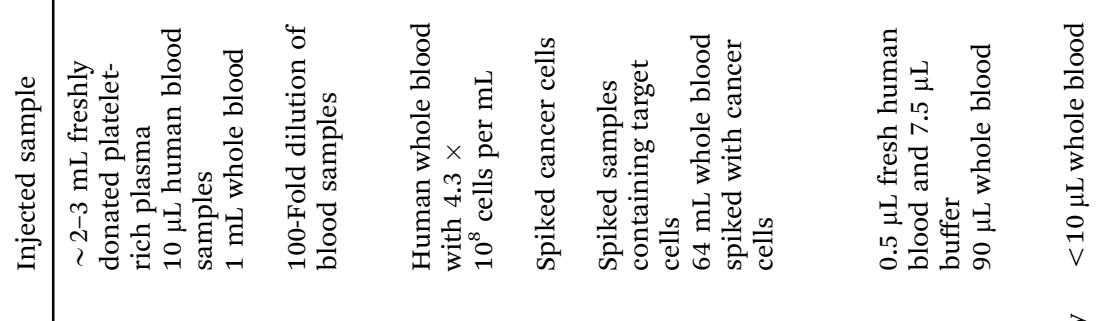

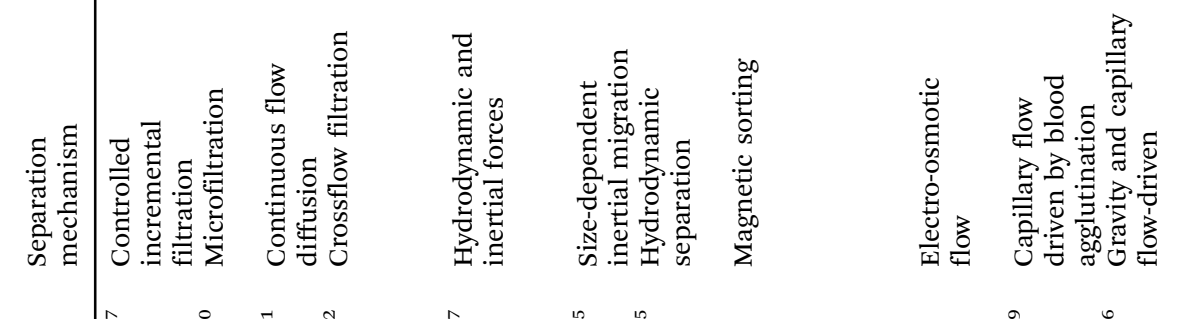

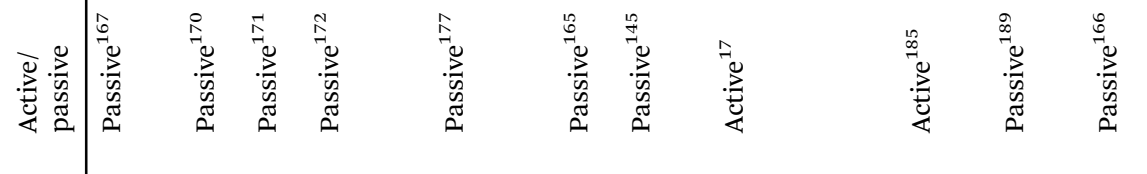

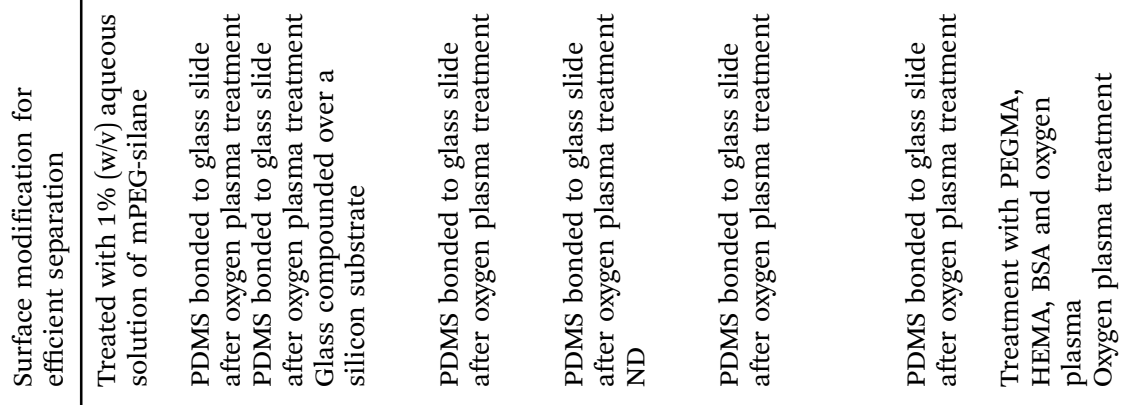




components. ${ }^{180}$ Filtration-based separation can address challenges regarding low expression of protein marker for CTCs (epithelial cell adhesion molecule or EpCAM) however, filtration will not be able to extract CTCs from other blood components with similar sizes. Hence, filter-free microfluidics provides an attractive platform for CTC isolation. ${ }^{181}$ Affinity-based separation can also be done for these blood components. ${ }^{181}$ The most clinically-validated current commercial technology available to separate EpCAM from whole blood which implements affinity-based separation is the FDAapproved CellSearch ${ }^{\circledR}$ System which contains ferrofluids with EpCAM antibodies. The specificity towards EpCAM clearance is high and ranging between 89 and 93\% using this technique. ${ }^{182,183}$ However, the sensitivity remains low with a very broad result distribution, and on the order of 27 to $70 \% .{ }^{182,183}$ Hence, other approaches are still being explored to separate EpCAM from blood.

A passive, multi-flow microfluidic channel was used to isolate CTCs in lung cancer patients (Table 5, entry 6). ${ }^{165}$ This device was designed for separation based on size-dependent inertial migration. Rotation-induced lift force $\left(F_{\Omega}\right)$ was the predominant force behind the size-based lateral migration and subsequent CTC isolation. The blood sample and phosphate buffer were introduced using a sample inlet and buffer inlet channel, merging to forming a sandwiched flow configuration in the main channel. The CTCs were collected from the inner outlet whereas other cells outside the size cut-off were collected from the outer outlet. To assess device performance, cancer cells spiked with poly(styrene) particles were used. Consequently, $>99 \%$ of the spiked samples were isolated with purity of $>87 \%$ and recovery of $>93 \%$. However, red blood cell contamination is an issue during sample preparation since the device isolated CTCs directly from whole blood thus additional cell lysis step for RBCs was required before separation. Samples were also not directly analysed by the instrument, which required immune-phenotyping post speciation.

Meanwhile, a passive, glass wedge-shaped microchip was also used to isolate CTCs from gastric cancer patients (Table 5, entry 7 and Fig. 4b). ${ }^{145}$ The wedge-shaped chamber provided functionality to the device by gradually decreasing the chamber height which allowed a wide outlet causing blood cells to not clog the channels. In addition, a pillar-array fluid distributor made the blood velocity distribution even across the entire wedge-shaped microchannel which enhanced the anti-clogging effect of the wedge-shaped chamber. RBC would flow and randomly rotate through the micro-chamber when the height of the micro-chamber was larger than the size of RBC but if otherwise, RBC would be oriented flat due to their disk-like shape during sample processing. Interestingly, WBCs would also go through this microchip even the cut-off size of this chip is smaller than the diameter of WBC due to the size-space amplification by the wedge-shaped micro chamber. This design resulted in a capture efficiency of $>93 \%$ for CTCs when processing the optimal blood volume of $2 \mathrm{~mL}$ at $200 \mu \mathrm{L} \mathrm{min}{ }^{-1}$.

Recognising the potential of magnetic sorting, active microfluidic devices were demonstrated for the isolation of CTCs from whole blood (Table 5, entry 8). ${ }^{17}$ The magnetic sorter was fabricated by using medical grade cyclic olefin copolymer for the inertial separation array device. PDMS was annealed to a glass slide to avoid further deformations caused by baking or heating during fabrication of the magnetic sorter. Meanwhile, cyclic olefin copolymer (COC) was used for the main chip. COCs are inexpensive polymers derived from cyclic olefin monomers and ethene. ${ }^{184}$ They are also transparent like PDMS except they have low elasticity and hydrophobic. Protein adsorption could be an issue on materials with hydrophobic surface but in this study, treatments to make the surface of the array device more hydrophilic were not applied. COC has the advantage of being a thermoplastic, hence devices can be made with high throughput by injection moulding. Separation relied solely on the device design rather than the material and occurred when the field gradient was intensified within the sorting channels using channels filled with "soft" (annealed) iron particles to act as magnetic micro-lenses. An increase in the applied magnetic field on inertially focused stream of cells efficiently depleted many leukocytes bound to magnetic beads, yielding $86 \%$ for CTCs and separating $\sim 99 \%$ for leukocytes, erythrocytes and platelets respectively. This result was supported by cell counting and phase contrast microscopy experiments. Compared to the previous passive microfluidic devices for blood component separation, the high separation efficiencies here is specific for only one or few blood components.

\subsection{Microfluidic devices for plasmapheresis}

The presence of important biomarkers and proteins in blood plasma makes plasma a desirable body fluid for clinical analysis. ${ }^{185}$ In order to achieve efficient separation for pointof-care applications, several different techniques were already applied such as geometrical obstructions, ${ }^{186}$ cross-flow filtration $^{187}$ and bifurcation law, referred to as the ZweifachFung effect ${ }^{188}$ or the process wherein shear is applied on cells driving them towards the centre of the channels of the microfluidic device forming a cell-free layer that can be captured at points where these channels divide (bifurcation points). ${ }^{160}$

Instead of hydrodynamic pumps, the electro-osmotic flow (EOF) has also been used to drive the fluid flow for plasmapheresis in micro-channels ${ }^{185}$ (Table 5, entry 9). The EOF is generated from the walls of the device when an electric field is applied. As the magnitude of the EOF correlates linearly with the electric field strength, fluidic separation mechanisms such as the Zweifach-Fung effect can be realised manipulating the electric field instead of a pump. By employing this separation mechanism, a yield of around $26 \%$ of blood plasma was collected from whole blood, with nearly $100 \%$ of the blood cells retained in the main channel. It should be noted that the volume of fresh human blood in the micro-channels was only $0.5 \mu \mathrm{L}$ (diluted with $7.5 \mu \mathrm{L}$ buffer).

Plasmapheresis was also realised using passive interlocked micropillar scaffolds fabricated from off-stoichiometry thiolenes (OSTE) ${ }^{189}$ (Table 5, entry 10 and Fig. 4c). OSTE is a group of polymer synthesized via step polymerization of thiol and -ene groups. ${ }^{190}$ By offsetting the stoichiometric ratios from 1:1, reactive groups in this polymer could be predicted making it easier for surface functionalization. ${ }^{190}$ Separation in this device 
happens when the blood sample clots upon material contact caused by deliberately adding an agglutination antibody to the material. The clots drastically minimize the surface area but allow for passage of the blood plasma through capillary action. When compared with previously established blood separation techniques such as centrifugation and membrane filtration (Fig. 4c, left), protein recovery rate improved from $\sim 73 \%$ using membrane filtration ${ }^{191}$ to $\sim 82 \%$ using this device. Effects of surface treatments using poly(ethylene glycol)methyl ether methacrylate (PEGMA) solution, hydroxyethylmethacrylate (HEMA) solution, bovine serum albumin (BSA) solution and oxygen plasma was also monitored and results showed that BSA treatment further improved the protein recovery rate to $91.7 \%$. However, it should be accounted for that BSA is a protein itself and the result of measurement of protein recovery using BCA (bicinchoninic) protein assay in this study could be a false positive.

A passive, capillary flow-driven microfluidic device used oxygen plasma to induce a wettability gradient in the cylindrical well fabricated between the hydrophilic top and bottom channels of a PDMS microfluidic device ${ }^{166}$ (Table 5, entry 11 and Fig. 4b). Upon introduction of blood sample within the hydrophilic device inlet, the difference in the Young-Laplace pressure induced a flow, with capillary action pulling the fluid front to the hydrophobic patch. The increasing contact angle at the hydrophobic patch decreased this force, significantly decreasing the fluid velocity. As the velocity decreased, the cells sedimented due to their higher density while the blood plasma continued to slowly rise, partially facilitated by its lower viscosity. Hence, the combination of gravity and capillarity underpins the plasma separation. When $<10 \mu \mathrm{L}$ of blood sample was injected in the device, $2 \mu \mathrm{L}$ of plasma was obtained in 15 min with a separation efficiency of $99.9 \%$. It is to be considered, however, that modification must be done for the device to be more applicable in continuous flow mode. The implementation of this approach aimed in this work towards diagnostics still faces challenges and further developments of the geometry of the system must be enabled to control the flow dynamics and facilitate continuous flow operation.

\subsection{Conclusions for microfluidic-based apheresis}

Microfluidic devices have great potential for use in blood apheresis, offering $>99 \%$ capture efficiencies for specific blood components. While parallel processing have enabled upscaling of microfluidic processing, microfluidic apheresis is currently more attractive in research since it can operate on very low blood volumes. Plasma separations, in particular, are highly sought after for diagnostic purposes. While some microfluidic approaches have demonstrated volumetric throughputs nearing those of 'traditional' approaches $\left(1 \mathrm{~mL} \min ^{-1}\right.$ for CIF $v s$. $50 \mathrm{~mL} \min ^{-1}$ for centrifugation), significant technical advances in parallel processing are required to progress these technologies from research and diagnostics to the collection of blood products at a commercial scale. In terms of material development, other haemocompatible polymers aside from PDMS, COC and OSTE such as poly(methyl methacrylate) (PMMA) must be explored to fully tap the potential of these devices in blood component extraction while considering the polymer properties required for device fabrication. Surface modification such as incorporating zwitterionic polymers (e.g. carboxybetaine or sulfobetaine) or even grafting anticoagulants such as heparin on device channels could be helpful in avoiding fouling as in other apheresis techniques such as membrane filtration.

\section{Perspectives}

Apheresis techniques, which may be utilized for donor blood component collection, removal of disease-provoking elements and overexpressed blood components for blood cell isolation are critical to bio-products separation and pathogen removal. Advantages and limitations for each technique are summarized in Table 6. Centrifugation, membranes, adsorbents and microfluidic devices represent the most established and relevant approaches to this mean and were discussed in detail in this review.

The gaps of current apheresis technologies are primarily linked to yet incomplete or non-cost-effective removal or separation efficiency of bio-products, potential side effects to patients and damage induced to cells during the extraction processes. Alternative processes benefiting from advanced materials with tuned interactions with blood components represent a key avenue to limit biofouling of surfaces and membranes and prevent inopportune cell activation. The scalability of such devices is often limited and implementing simpler fabrication methods could lead to improvements towards more scalable technologies. The impact of blood coagulation proteins for blood apheresis are not prioritized thus preventing the massive application of these technologies in clinical settings.

Hence, future work must be directed on the interfacial chemistries between the blood and the material it interacts with to have a better understanding on the exact mechanism of contact, the functional groups that react and the configuration

Table 6 Advantages and limitations of current and emerging apheresis techniques

\begin{tabular}{|c|c|c|}
\hline Apheresis technique & Advantages & Limitations \\
\hline Centrifugal-based & Most utilized and established & $\begin{array}{l}\text { High variabilities in separation time, low reproducibility } \\
\text { and selectivity; strong mechanical shear stress inducing platelet activation }\end{array}$ \\
\hline Membrane-based & Scalable and versatile & Low selectivity especially towards components of same size \\
\hline Adsorbent-based & Highly selective & Low hemocompatibility of ligand materials \\
\hline Microfluidic-based & $\begin{array}{l}\text { Highly specific with capture } \\
\text { efficiencies }>99 \% \text {; low processing }\end{array}$ & Fouling of microfluidic components \\
\hline
\end{tabular}

volumes required 
of the blood molecule that interacted with these functional groups. Future studies on these aspects are especially relevant now when there is an increasing trend towards incorporation of emerging materials whose properties are not yet fully understood, such as inorganic nanofillers incorporated with membrane and sorbents for enhanced mechanical property.

Biocompatible materials such as amphiphilic/zwitterionic polymers can also be explored as coating materials for these devices for enhanced haemocompatibility. Extensive haemocompatibility testing inclusive on the effects of the selected apheresis technology on coagulation proteins must be done as part of material development to aid in the translation of these technologies towards actual apheresis procedures. By comparing the separation efficiencies and percent recoveries of each technique, this review offers a selection of the possible ways of addressing the limitations in blood apheresis giving emphasis on the effects of surface modification methods and material design to enhance separation performance.

\section{Author contributions}

Christine Jurene O. Bacal: conceptualization, writing - original draft. Ludovic F. Dumee: conceptualization, supervision, writing - review and editing. Karen M. Dwyer: supervision, writing - review and editing. James W. Maina, Harshal H. Nandurkar, Yung Chang, Maryam T. Khaleel and Rosanne M. Guijt: writing - review and editing.

\section{Conflicts of interest}

There are no conflicts to declare.

\section{Acknowledgements}

L. F. D. acknowledges financial support from the Discovery Early Career Researcher Award (DECRA) from the Australian Research Council (ARC) (180100130) and from Khalifa University of Science and Technology under project RC2-2019-007.

\section{References}

1 J. Hardwick, ISBT Sci. Ser., 2008, 3, 148-176.

2 M. El Ekiaby, ISBT Sci. Ser., 2017, 12, 87-90.

3 C. Ronco and W. R. Clark, Nat. Rev. Nephrol., 2018, 14, 394-410.

4 W. R. Clark, F. Ferrari, G. La Manna and C. Ronco, Contrib. Nephrol., 2017, 190, 43-57.

5 G. M. Whitesides, Nature, 2006, 442, 368-373.

6 What is Apheresis? https:/www.petermac.org/services/treat ment/haematological-treatments/apheresis/what-apheresis, (accessed October 13, 2021).

7 J. L. Winters, Hematology Am. Soc. Hematol. Educ. Program, 2012, 2012, 7-12.

8 N. Bose and H. Kanzariya, Indian J. Anaesth., 2014, 58, 672-678.
9 M. E. Williams and R. A. Balogun, Clin. J. Am. Soc. Nephrol., 2014, 9, 181-190.

10 C. Klaus, B. Plaimauer, J.-D. Studt, F. Dorner, B. Lämmle, P. M. Mannucci and F. Scheiflinger, Blood, 2004, 103, 4514.

11 E. Sumida, Y. Iwasaki, K. Akiyoshi and S. Kasugai, J. Pharmacol. Sci., 2006, 101, 91-97.

12 N. Worel, B. Mansouri Taleghani and E. Strasser, Transfus. Med. Hemother., 2019, 46, 394-406.

13 R. A. Ward, J. K. Leypoldt, W. R. Clark, C. Ronco, G. J. Mishkin and E. P. Paganini, Semin. Dial., 2001, 14, 160-174.

14 S. Gosselin, D. N. Juurlink, J. T. Kielstein, M. Ghannoum, V. Lavergne, T. D. Nolin and R. S. Hoffman, Clin. Toxicol., 2014, 52, 856-867.

15 A. M. Grunbaum, S. Kazim, M. Ghannoum, M.-A. KallaiSanfacon, R. Mangel, E. Villeneuve and S. Gosselin, Clin. Toxicol., 2013, 51, 270-271.

16 A. Urbansky, P. Ohlsson, A. Lenshof, F. Garofalo, S. Scheding and T. Laurell, Sci. Rep., 2017, 7, 17161.

17 A. Mishra, T. D. Dubash, J. F. Edd, M. K. Jewett, S. G. Garre, N. M. Karabacak, D. C. Rabe, B. R. Mutlu, J. R. Walsh, R. Kapur, S. L. Stott, S. Maheswaran, D. A. Haber and M. Toner, Proc. Natl. Acad. Sci. U. S. A., 2020, 117, 16839.

18 A. P. Sanchez, R. Cunard and D. M. Ward, J. Clin. Apher., 2013, 28, 20-29.

19 M. Kersaudy-Kerhoas and E. Sollier, Lab Chip, 2013, 13, 3323-3346.

20 S. C. Gifford, B. C. Strachan, H. Xia, E. Vörös, K. Torabian, T. A. Tomasino, G. D. Griffin, B. Lichtiger, F. M. Aung and S. S. Shevkoplyas, PLoS One, 2018, 13, e0190827.

21 L. Wiegmann, D. A. De Zélicourt, O. Speer, A. Muller, J. S. Goede, B. Seifert and V. Kurtcuoglu, Front. Physiol., 2017, 8, 731.

22 S. Fukuda and G. W. Schmid-Schönbein, J. Leukoc. Biol., 2002, 72, 133-139.

23 A. Seltsam, Front. Med., 2017, 4, 219.

24 G. de Sousa and J. Seghatchian, Transfus. Apher. Sci., 2006, 34, 77-83.

25 B. Puppe and E. J. Kingdon, Clin. Kidney J., 2014, 7, 201-205.

26 C. Hafer, P. Golla, M. Gericke, G. Eden, G. Beutel, J. J. Schmidt, B. M. W. Schmidt, S. De Reys and J. T. Kielstein, Int. Urol. Nephrol., 2016, 48, 133-138.

27 M. E. Janssens and S. Wakelin, Eur. Oncol. Haematol., 2018, 14, 105-109.

28 S. O. Catarino, R. O. Rodrigues, D. Pinho, J. M. Miranda, G. Minas and R. Lima, Micromachines, 2019, 10(9), 593.

29 J. Korsak and Z. Wańkowicz, Blood Purif., 2016, 41, 1-10.

30 D. M. Ward, J. Clin. Apher., 2011, 26, 230-238.

31 A. G. Perez, J. F. Lana, A. A. Rodrigues, A. C. Luzo, W. D. Belangero and M. H. Santana, ISRN Hematol., 2014, 2014, 176060.

32 J. Schwartz, A. Padmanabhan, N. Aqui, R. A. Balogun, L. Connelly-Smith, M. Delaney, N. M. Dunbar, V. Witt, Y. Wu and B. H. Shaz, J. Clin. Apher., 2016, 31, 149-338.

33 J. Schwartz, J. L. Winters, A. Padmanabhan, R. A. Balogun, M. Delaney, M. L. Linenberger, Z. M. Szczepiorkowski, 
M. E. Williams, Y. Wu and B. H. Shaz, J. Clin. Apher., 2013, 28, 145-284.

34 Z. M. Szczepiorkowski, J. L. Winters, N. Bandarenko, H. C. Kim, M. L. Linenberger, M. B. Marques, R. Sarode, J. Schwartz, R. Weinstein and B. H. Shaz, J. Clin. Apher., 2010, 25, 83-177.

35 J. E. Mancuso, A. Jayaraman and W. D. Ristenpart, PLoS One, 2018, 13, e0203270.

36 D. M. Dohan Ehrenfest, N. R. Pinto, A. Pereda, P. Jiménez, M. D. Corso, B.-S. Kang, M. Nally, N. Lanata, H.-L. Wang and M. Quirynen, Platelets, 2018, 29, 171-184.

37 E. S. Lourenço, G. G. Alves, R. de Lima Barbosa, C. N. Spiegel, R. C. de Mello-Machado, S. Al-Maawi, S. Ghanaati and C. F. de Almeida Barros Mourão, J. Biomed. Mater. Res., Part B, 2021, 109, 60-68.

38 X. H. Zheng, C. Cui, X. X. Zhou, Y. X. Zeng and W. H. Jia, Chin. J. Cancer, 2013, 32, 667-672.

39 M. Lu, D. L. Lezzar, E. Vörös and S. S. Shevkoplyas, J. Blood Med., 2019, 10, 37.

40 R. Dhurat and M. Sukesh, J. Cutan. Aesthet. Surg., 2014, 7, 189-197.

41 D. Basu and R. Kulkarni, Indian J. Anaesth., 2014, 58, 529-537.

42 E. Hussein and A. Enein, Lab. Med., 2014, 45, 238-243.

43 L. Bongo, R. Bhatia and L. S. Lamb, Jr., Blood, 2018, 132, 5693.

44 P. Kes, M. E. Janssens, N. Bašić-Jukić and M. Kljak, Transfusion, 2016, 56, 3065-3072.

45 M. Brambilla, L. Rossetti, C. Zara, P. Canzano, P. L. A. Giesen, E. Tremoli and M. Camera, Platelets, 2018, 29, 406-414.

46 H. Fernandez-Munoz, C. Castilla-Llorente, E. M. Plaza, C. Martinez-Millan, I. Heras, P. Iniesta, M. L. Amigo, F. Ferrer-Marin, M. J. Candela, M. L. Lozano, V. Vicente and J. Rivera, Blood Transfus., 2018, 16, 273-278.

47 A. K. Pulsfort, T. P. Wolter and N. Pallua, Ann. Plast. Surg., 2011, 66, 292-295.

48 R. Landesberg, M. Roy and R. S. Glickman, J. Oral Maxillofac. Surg., 2000, 58, 297-300; discussion 300-291.

49 O. Bausset, L. Giraudo, J. Veran, J. Magalon, J. M. Coudreuse, G. Magalon, C. Dubois, N. Serratrice, F. Dignat-George and F. Sabatier, Biores. Open Access, 2012, 1, 115-123.

50 E. Anitua, J. J. Aguirre, J. Algorta, E. Ayerdi, A. I. Cabezas, G. Orive and I. Andia, J. Biomed. Mater. Res., Part B, 2008, 84, 415-421.

51 M. Punzel, A. Kozlova, A. Quade, A. H. Schmidt and R. Smith, Vox Sang., 2017, 112, 586-594.

52 C. H. Jo, Y. H. Roh, J. E. Kim, S. Shin and K. S. Yoon, J. Oral Implantol., 2013, 39, 525-532.

53 J. Cadamuro, C. Mrazek, A. B. Leichtle, U. Kipman, T. K. Felder, H. Wiedemann, H. Oberkofler, G. M. Fiedler and E. Haschke-Becher, Biochem. Med., 2018, 28, 010704.

54 D. M. Pegtel, K. Cosmopoulos, D. A. Thorley-Lawson, M. A. van Eijndhoven, E. S. Hopmans, J. L. Lindenberg, T. D. de Gruijl, T. Würdinger and J. M. Middeldorp, Proc. Natl. Acad. Sci. U. S. A., 2010, 107, 6328-6333.
55 G. Filardo, E. Kon, M. T. Pereira Ruiz, F. Vaccaro, R. Guitaldi, A. Di Martino, A. Cenacchi, P. M. Fornasari and M. Marcacci, Knee Surg., Sports Traumatol., Arthrosc., 2012, 20, 2082-2091.

56 N. Tynngård, Transfus. Apher. Sci., 2009, 41, 97-104.

57 H. J. Gurland, M. J. Lysaght, W. Samtleben and B. Schmidt, Int. J. Artif. Organs, 1984, 7, 35-38.

58 C. Okafor, D. M. Ward, M. H. Mokrzycki, R. Weinstein, P. Clark and R. A. Balogun, J. Clin. Apher., 2010, 25, 240-249.

59 A. Bruil, T. Beugeling, J. Feijen and W. G. van Aken, Transfus. Med. Rev., 1995, 9, 145-166.

60 A. Sueoka, Ther. Apher., 1998, 2, 78-86.

61 A. Sueoka, Ther. Apher., 1997, 1, 135-146.

62 T. Xiang, C. Cheng and C. Zhao, J. Membr. Sep. Technol., 2014, 3, 162.

63 J. F. Hester, Doctor of Philosophy in Polymers Dissertation, Massachusetts Institute of Technology, 1993.

64 A. Higuchi, K. Sugiyama, B. O. Yoon, M. Sakurai, M. Hara, M. Sumita, S.-i. Sugawara and T. Shirai, Biomaterials, 2003, 24, 3235-3245.

65 L. Y. Ng, A. W. Mohammad, C. P. Leo and N. Hilal, Desalination, 2013, 308, 15-33.

66 C.-C. Lien, P.-J. Chen, A. Venault, S.-H. Tang, Y. Fu, G. V. Dizon, P. Aimar and Y. Chang, J. Membr. Sci., 2019, 584, 148-160.

67 P.-S. Liu, Q. Chen, S.-S. Wu, J. Shen and S.-C. Lin, J. Membr. Sci., 2010, 350, 387-394.

68 L. Zhu, F. Liu, X. Yu and L. Xue, ACS Appl. Mater. Interfaces, 2015, 7, 17748-17755.

69 S. Singh and A. Kumar, Biotechnol. J., 2009, 4, 1140-1151.

70 A. Bruil, H. A. Oosterom, I. Steneker, B. J. Al, T. Beugeling, W. G. van Aken and J. Feijen, J. Biomed. Mater. Res., 1993, 27, 1253-1268.

71 A. Bruil, W. G. Van Aken, T. Beugeling, J. Feijen, I. Steneker, J. G. Huisman and H. K. Prins, J. Biomed. Mater. Res., 1991, 25, 1459-1480.

72 S. Teraoka, Y. Hayasaka, H. Shoji, M. Mineshima, T. Suzuki, Y. Sasaki, M. Sato, T. Hoshino, K. Era and T. Tojinbara, et al., ASAIO Trans., 1988, 34, 608-612.

73 R. R. Sharma and N. Marwaha, Asian J. Transfus. Sci., 2010, 4, 3-8.

74 A. W. Neumann, D. R. Absolom, C. J. van Oss and W. Zingg, Cell Biophys., 1979, 1, 79-92.

75 W. A. Zisman, Contact Angle, Wettability, and Adhesion, American Chemical Society, 1964, ch. 1, vol. 43, pp. 1-51.

76 J. Kjeldsen-Kragh and E. Golebiowska, Vox Sang., 2002, 82, 127-130.

77 R. R. Gammon, S. A. Strayer, N. L. Avery and P. D. Mintz, Ann. Clin. Lab. Sci., 2000, 30, 195-199.

78 I. Steneker and J. Biewenga, Transfusion, 1991, 31, 40-46.

79 S. Dzik, Transfus. Med. Rev., 1993, 7, 65-77.

80 S. H. Ye, J. Watanabe and K. Ishihara, J. Biomater. Sci., Polym. Ed., 2004, 15, 981-1001.

81 M.-C. Sin, S.-H. Chen and Y. Chang, Polym. J., 2014, 46, 436-443. 
82 PuriBlood, http://www.puriblood.com/index.php?lang=en, (accessed March 13, 2021).

83 A. L. Lewis, R. N. Freeman, R. P. Redman, L. A. Tolhurst, L. C. Kirkwood, D. M. Grey and T. A. Vick, J. Mater. Sci.: Mater. Med., 2003, 14, 39-45.

84 S. Clarke, M. C. Davies, C. J. Roberts, S. J. Tendler, P. M. Williams, V. O'Byrne, A. L. Lewis and J. Russell, Langmuir, 2000, 16, 5116-5122.

85 A. Higuchi, S.-i. Yamamiya, B. O. Yoon, M. Sakurai and M. Hara, J. Biomed. Mater. Res., Part A, 2004, 68A, 34-42.

86 Y.-W. Chen, A. Venault, J.-F. Jhong, H.-T. Ho, C.-C. Liu, R.-H. Lee, G.-H. Hsiue and Y. Chang, J. Membr. Sci., 2017, 537, 209-219.

87 E. Gérard, E. Bessy, G. Hénard, T. Verpoort and J. MarchandBrynaert, J. Biomed. Mater. Res., Part B, 2012, 100, 1513-1523.

88 F. Sadeghi, A. Ajji and P. J. Carreau, J. Membr. Sci., 2007, 292, 62-71.

89 F. Sadeghi, A. Ajji and P. J. Carreau, Polym. Eng. Sci., 2007, 47, 1170-1178.

90 Y. Cao, J. Liu, R. Zhong, Q. Yu and H. Wang, Artif. Cells, Blood Substitutes, 2012, 40, 317-325.

91 E. J. Kim, G.-D. Yeo, C.-M. Pai and I.-K. Kang, J. Biomed. Mater. Res., Part B, 2009, 90B, 849-856.

92 P. V. Mayuri, A. Bhatt, A. Sabaweeswaran and P. Ramesh, J. Biomater. Sci., Polym. Ed., 2020, 1-18, DOI: 10.1080/ 09205063.2020.1851559.

93 R. Hirano, K. Namazuda, J. Suemitsu, T. Harashima and N. Hirata, Transfus. Apher. Sci., 2017, 56, 649-653.

94 R. Vanholder, A. Argilés, U. Baurmeister, P. Brunet, W. Clark, G. Cohen, P. P. De Deyn, R. Deppisch, B. Descamps-Latscha, T. Henle, A. Jorres, Z. A. Massy, M. Rodriguez, B. Stegmayr, P. Stenvinkel and M. L. Wratten, Int. J. Artif. Organs, 2001, 24, 695-725.

95 M. Chmielewski, G. Cohen, A. Wiecek and J. Jesús Carrero, Semin. Nephrol., 2014, 34, 118-134.

96 C. Ronco and G. La, Manna, Contrib. Nephrol., 2017, 190, 124-133.

97 A. C. Yamashita, H. Masaki, E. Kobayashi and T. Sukegawa, Hemodial. Int., 2015, 19, S20-S25.

98 M. M. Amiji, J. Biomater. Sci., Polym. Ed., 1997, 8, 281-298.

99 M. Faria, C. Moreira, T. Eusébio, P. Brogueira and M. N. de Pinho, Cellulose, 2020, 27, 3847-3869.

100 N. Said, M. Nidzhom, H. Hasbullah, A. Ismail, P. Goh, M. Hafiz, M. H. Othman, S. Abdullah, S. Kadir, A. Kadir and F. Kamal, Mal. J. Fund. Appl. Sci., 2020, 16, 1-5.

101 M. N. Z. Abidin, P. S. Goh, A. F. Ismail, M. H. D. Othman, H. Hasbullah, N. Said, S. H. S. A. Kadir, F. Kamal, M. S. Abdullah and B. C. Ng, Mater. Sci. Eng., C, 2016, 68, 540-550.

102 P. G. Kerr and L. Huang, Nephrology, 2010, 15, 381-385.

103 A. K. Cheung, C. J. Parker, L. A. Wilcox and J. Janatova, Kidney Int., 1990, 37, 1055-1059.

104 Z. Zhang, S. Chen, Y. Chang and S. Jiang, J. Phys. Chem. B, 2006, 110, 10799-10804.

105 R. M. Hakim, D. T. Fearon, J. M. Lazarus and C. S. Perzanowski, Kidney Int., 1984, 26, 194-200.
106 J. C. Hutter, M. J. Kuehnert, R. R. Wallis, A. D. Lucas, S. Sen and W. R. Jarvis, JAMA, 2000, 283, 2128-2134.

107 M. E. Neumann, Nephrol. News Issues, 1996, 10(9), 11.

108 H. D. Humes, W. H. Fissell and K. Tiranathanagul, Kidney Int., 2006, 69, 1115-1119.

109 S. P. Adiga, C. Jin, L. A. Curtiss, N. A. Monteiro-Riviere and R. J. Narayan, Wiley Interdiscip. Rev.: Nanomed. Nanobiotechnol., 2009, 1, 568-581.

110 A. Gao, F. Liu and L. Xue, J. Membr. Sci., 2014, 452, 390-399.

111 M. Irfan, A. Idris, N. M. Yusof, N. F. M. Khairuddin and H. Akhmal, J. Membr. Sci., 2014, 467, 73-84.

112 J. R. Colvin, Can. J. Chem., 1952, 30, 831-834.

113 C. H. Trinh, D. P. Smith, A. P. Kalverda, S. E. V. Phillips and S. E. Radford, Proc. Natl. Acad. Sci. U. S. A., 2002, 99, 9771-9776.

114 F. Galli, S. Rovidati, L. Chiarantini, G. Campus, F. Canestrari and U. Buoncristiani, Kidney Int., 1998, 54, 580-589.

115 V. Sepe, M. Gregorini, T. Rampino, P. Esposito, R. Coppo, F. Galli and C. Libetta, BMC Nephrol., 2019, 20, 412.

116 M. Kiaii, M. Aritomi, M. Nagase, M. Farah and B. Jung, J. Artif. Organs, 2019, 22, 307-315.

117 O. E. M. ter Beek, D. Pavlenko and D. Stamatialis, J. Membr. Sci., 2020, 604, 118068.

118 M. Tijink, J. Janssen, M. Timmer, J. Austen, Y. Aldenhoff, J. Kooman, L. Koole, J. Damoiseaux, R. van Oerle, Y. Henskens and D. Stamatialis, J. Mater. Chem. B, 2013, 1, 6066-6077.

119 Y. Liu, Y. Su, X. Zhao, Y. Li, R. Zhang and Z. Jiang, J. Membr. Sci., 2015, 486, 195-206.

120 M. Adeli, E. Mehdipour and M. Bavadi, J. Appl. Polym. Sci., 2010, 116, 2188-2196.

121 T. Xiang, C.-D. Luo, R. Wang, Z.-Y. Han, S.-D. Sun and C.-S. Zhao, J. Membr. Sci., 2015, 476, 234-242.

122 L. Wang, J. Wang, X. Gao, Z. Liang, B. Zhu, L. Zhu and Y. Xu, Polym. Chem., 2014, 5, 2836-2842.

123 K. Madhavan Nampoothiri, N. R. Nair and R. P. John, Bioresour. Technol., 2010, 101, 8493-8501.

124 J. K. Oh, Soft Matter, 2011, 7, 5096-5108.

125 M. M. Flanders, R. Crist and G. M. Rodgers, Clin. Chem., 2003, 49, 169-172.

126 M. Z. Fahmi, M. Wathoniyyah, M. Khasanah, Y. Rahardjo, S. Wafiroh and Abdulloh, RSC Adv., 2018, 8, 931-937.

127 M. Leeman, J. Choi, S. Hansson, M. U. Storm and L. Nilsson, Anal. Bioanal. Chem., 2018, 410, 4867-4873.

128 M.-M. Tu, J.-J. Xu and Y.-R. Qiu, RSC Adv., 2019, 9, 6254-6266.

129 N. J. Kaleekkal, A. Thanigaivelan, M. Durga, R. Girish, D. Rana, P. Soundararajan and D. Mohan, Ind. Eng. Chem. Res., 2015, 54, 7899-7913.

130 M. Ghannoum, J. Bouchard, T. D. Nolin, G. Ouellet and D. M. Roberts, Semin. Dial., 2014, 27, 350-361.

131 J. H. Salazar, Lab. Med., 2014, 45, e19-e20.

132 L. B. VanWagner and R. M. Green, JAMA, 2015, 313, 516-517.

133 Q. Li, W. Zhao, H. Guo, J. Yang, J. Zhang, M. Liu, T. Xu, Y. Chen and L. Zhang, ACS Appl. Mater. Interfaces, 2020, 12, 25546-25556. 
134 C. Tetta, R. Bellomo, A. Brendolan, P. Piccinni, A. Digito, M. Dan, M. Irone, G. Lonnemann, D. Moscato, J. Buades, G. La Greca and C. Ronco, Kidney Int., 1999, 56, S15-S19.

135 G. La Greca, A. Brendolan, P. M. Ghezzi, R. De Smet, C. Tetta, R. Gervasio and C. Ronco, Int. J. Artif. Organs, 1998, 21, 303-308.

136 K. Cao, C. P. Siepermann, M. Yang, A. M. Waas, N. A. Kotov, M. D. Thouless and E. M. Arruda, Adv. Funct. Mater., 2013, 23, 2072-2080.

137 R.-L. Liu, Y. Wang, X.-L. Ge, P. Yu, H.-Q. Liu, M.-C. Wang, W. Lu and Q. Fu, J. Biomater. Sci., Polym. Ed., 2017, 28, 1444-1468.

138 S. E. Cowper, H. S. Robin, S. M. Steinberg, L. D. Su, S. Gupta and P. E. LeBoit, Lancet, 2000, 356, 1000-1001.

139 A. Sueoka, Ther. Apher., 1997, 1, 271-283.

140 D. Pavlenko, D. Giasafaki, G. Charalambopoulou, E. van Geffen, K. G. F. Gerritsen, T. Steriotis and D. Stamatialis, Sci. Rep., 2017, 7, 14914.

141 C. A. Howell, S. R. Sandeman, Y. Zheng, S. V. Mikhalovsky, V. G. Nikolaev, L. A. Sakhno and E. A. Snezhkova, Carbon, 2016, 97, 134-146.

142 Y. Yang, S. Yin, C. He, X. Wu, J. Yin, J. Zhang, L. Ma, W. Zhao, C. Cheng and C. Zhao, J. Mater. Chem. B, 2020, 8, 1960-1970.

143 R. S. Bedi, D. E. Beving, L. P. Zanello and Y. Yan, Acta Biomater., 2009, 5, 3265-3271.

144 Y. Yu, Chin. Sci. Bull., 2013, 58, 4357-4361.

145 X. Song, K. Wang, C.-Q. Tang, W.-W. Yang, W.-F. Zhao and C.-S. Zhao, Biomacromolecules, 2018, 19, 1966-1978.

146 M. Eberhardson, P. Marits, M. Jones, P. Jones, P. Karlen, M. Karlsson, G. Cotton, K. Woznica, B. Maltman, H. Glise and O. Winqvist, Clin. Immunol., 2013, 149, 73-82.

147 J. H. Kang, M. Super, C. W. Yung, R. M. Cooper, K. Domansky, A. R. Graveline, T. Mammoto, J. B. Berthet, H. Tobin, M. J. Cartwright, A. L. Watters, M. Rottman, A. Waterhouse, A. Mammoto, N. Gamini, M. J. Rodas, A. Kole, A. Jiang, T. M. Valentin, A. Diaz, K. Takahashi and D. E. Ingber, Nat. Med., 2014, 20, 1211-1216.

148 J. Ciambella, D. C. Stanier and S. S. Rahatekar, Composites, Part B, 2017, 109, 129-137.

149 N. M. Osmond, Adsorpt. Sci. Technol., 2000, 18, 529-539.

150 S. Chen, Y. Cao and J. Feng, ACS Appl. Mater. Interfaces, 2014, 6, 349-356.

151 A. Y. Rad, H. Yavuz, M. Kocakulak and A. Denizli, Macromol. Biosci., 2003, 3, 471-476.

152 W. Shi, Y. Shen, H. Jiang, C. Song, Y. Ma, J. Mu, B. Yang and D. Ge, J. Membr. Sci., 2010, 349, 333-340.

153 W. Yantasee, G. E. Fryxell, G. A. Porter, K. Pattamakomsan, V. Sukwarotwat, W. Chouyyok, V. Koonsiripaiboon, J. Xu and K. N. Raymond, Nanomedicine, 2010, 6, 1-8.

154 Y. Lin, S. K. Fiskum, W. Yantasee, H. Wu, S. V. Mattigod, E. Vorpagel, G. E. Fryxell, K. N. Raymond and J. Xu, Environ. Sci. Technol., 2005, 39, 1332-1337.

155 D. W. Whisenhunt, M. P. Neu, Z. Hou, J. Xu, D. C. Hoffman and K. N. Raymond, Inorg. Chem., 1996, 35, 4128-4136.

156 J. Chen, W. Han, R. Su, J. Chen, W. Zong, Y. Wang, W. Wang, G. Cheng, L. Ou and Y. Yu, Artif. Cells, Nanomed., Biotechnol., 2017, 45, 174-183.
157 L. Tan, R. He, Y. Li, Y. Liang, H. Li and Y. Tang, J. Chromatogr. A, 2016, 1459, 1-8.

158 N. Wu, Z. Luo, Y. Ge, P. Guo, K. Du, W. Tang, W. Du, A. Zeng, C. Chang and Q. Fu, J. Pharm. Anal., 2016, 6, 157-164.

159 T. Agishi, K. Takahashi, T. Yagisawa and K. Ota, ASAIO Trans., 1991, 37, M496-M498.

160 M. E. Warkiani, L. Wu, A. K. Tay and J. Han, Annu. Rev. Biomed. Eng., 2015, 17, 1-34.

161 Z. T. Yu, K. M. Aw Yong and J. Fu, Small, 2014, 10, 1687-1703.

162 A. A. S. Bhagat, H. Bow, H. W. Hou, S. J. Tan, J. Han and C. T. Lim, Med. Biol. Eng. Comput., 2010, 48, 999-1014.

163 H. W. Hou, A. A. S. Bhagat, W. C. Lee, S. Huang, J. Han and C. T. Lim, Micromachines, 2011, 2, 319-343.

164 J. C. McDonald and G. M. Whitesides, Acc. Chem. Res., 2002, 35, 491-499.

165 J. Zhou, A. Kulasinghe, A. Bogseth, K. O’Byrne, C. Punyadeera and I. Papautsky, Microsyst. Nanoeng., 2019, 5, 8.

166 M. S. Maria, P. E. Rakesh, T. S. Chandra and A. K. Sen, Sci. Rep., 2017, 7, 43457.

167 H. Xia, B. C. Strachan, S. C. Gifford and S. S. Shevkoplyas, Sci. Rep., 2016, 6, 35943.

168 A. Papra, A. Bernard, D. Juncker, N. B. Larsen, B. Michel and E. Delamarche, Langmuir, 2001, 17, 4090-4095.

169 K. M. Kovach, J. R. Capadona, A. S. Gupta and J. A. Potkay, J. Biomed. Mater. Res., Part A, 2014, 102, 4195-4205.

170 A. Mohd Noor, T. Masuda and F. Arai, ROBOMECH J., 2020, 7, 5 .

171 P. Sethu, A. Sin and M. Toner, Lab Chip, 2006, 6, 83-89.

172 X. Chen, D. F. Cui, C. C. Liu and H. Li, Sens. Actuators, B, 2008, 130, 216-221.

173 X. Chen, D. F. Cui, C. C. Liu and H. Li, Sens. Actuators, B, 2008, 130, 216-221.

174 H. Jang, M. R. Haq, J. Ju, Y. Kim, S.-M. Kim and J. Lim, Micromachines, 2017, 8, 67.

175 P. Bacchin, M. Meireles and P. Aimar, Desalination, 2002, 145, 139-146.

176 Y. Lee and M. M. Clark, J. Membr. Sci., 1998, 149, 181-202.

177 B. Lombodorj, H. C. Tseng, H. Y. Chang, Y. W. Lu, N. Tumurpurev, C. W. Lee, B. Ganbat, R. G. Wu and F. G. Tseng, Micromachines, 2020, 11(3), 275.

178 S. Ookawara, M. Agrawal, D. Street and K. Ogawa, Chem. Eng. Sci., 2007, 62, 2454-2465.

179 P. Li, Z. S. Stratton, M. Dao, J. Ritz and T. J. Huang, Lab Chip, 2013, 13, 602-609.

180 W. J. Allard, J. Matera, M. C. Miller, M. Repollet, M. C. Connelly, C. Rao, A. G. J. Tibbe, J. W. Uhr and L. W. M. M. Terstappen, Clin. Cancer Res., 2004, 10, 6897.

181 Y. Dong, A. M. Skelley, K. D. Merdek, K. M. Sprott, C. Jiang, W. E. Pierceall, J. Lin, M. Stocum, W. P. Carney and D. A. Smirnov, J. Mol. Diagn., 2013, 15, 149-157.

182 B. Hong and Y. Zu, Theranostics, 2013, 3, 377-394.

183 L. Wang, P. Balasubramanian, A. P. Chen, S. Kummar, Y. A. Evrard and R. J. Kinders, Semin. Oncol., 2016, 43, 464-475. 
184 P. S. Nunes, P. D. Ohlsson, O. Ordeig and J. P. Kutter, Microfluid. Nanofluid., 2010, 9, 145-161.

185 H. Jiang, X. Weng, C. H. Chon, X. Wu and D. Li, J. Micromech. Microeng., 2011, 21, 085019.

186 S. Choi, S. Song, C. Choi and J. K. Park, Lab Chip, 2007, 7, 1532-1538.

187 T. Tachi, N. Kaji, M. Tokeshi and Y. Baba, Anal. Chem., 2009, 81, 3194-3198.

188 S. Yang, B. Ji, A. Undar and J. D. Zahn, ASAIO J., 2006, 52, 698-704.

189 W. Guo, J. Hansson and W. van der Wijngaart, Anal. Chem., 2020, 92, 6194-6199.

190 M. Hillmering, G. Pardon, A. Vastesson, O. Supekar, C. F. Carlborg, B. D. Brandner, W. van der Wijngaart and T. Haraldsson, Microsyst. Nanoeng., 2016, 2, 15043.

191 J. Hauser, G. Lenk, J. Hansson, O. Beck, G. Stemme and N. Roxhed, Anal. Chem., 2018, 90, 13393-13399.

192 Z.-Y. Tao, H. Xia, J. Cao and Q. Gao, Malar. J., 2011, 10, 251. 193 C. Ronco, C. Crepaldi, A. Brendolan, L. Bragantini, V. d'Intini, P. Inguaggiato, M. Bonello, B. Krause, R. Deppisch and H. Goehl, Nephrol. Dial. Transplant., 2003, 18, vii10-vii20.

194 R. M. Schaefer, W. Rautenberg, S. Neumann, A. Heidland and W. H. Hörl, Clin. Nephrol., 1986, 26(Suppl 1), S35-S38.

195 L. J. Langsdorf, L. G. Krankel and A. L. Zydney, ASAIO J., 1993, 39, M767-M772.

196 F. Aucella, M. Vigilante, G. Gatta, E. Grandone, D. Colaizzo, M. Margaglione, S. Modoni and C. Stallone, Artif. Organs, 2002, 26, 543-545.

197 N. Meert, S. Eloot, E. Schepers, H.-D. Lemke, A. Dhondt, G. Glorieux, M. Van Landschoot, M.-A. Waterloos and R. Vanholder, Nephrol., Dial., Transplant., 2011, 26, 2624-2630.

198 J. K. Leypoldt, A. K. Cheung, L. Y. Agodoa, J. T. Daugirdas, T. Greene and P. R. Keshaviah, Kidney Int., 1997, 51, 2013-2017.

199 W. R. Clark, R. J. Hamburger and M. J. Lysaght, Kidney Int., 1999, 56, 2005-2015.

200 EXELTRA $^{\mathrm{TM}}$ Dialyzer, Single Use, 2003, p. K030974.

201 FX high-flux and FX low-flux dialyzers, https://www.fresenius medicalcare.asia/en/healthcare-professionals/hemodialysis/ dialyzers/fx-high-and-low-flux-dialyzers/, (accessed November 2, 2020).

202 S. Sibbel, A. Hunt, S. Laplante, W. Beck, M. Gellens and S. M. Brunelli, ASAIO J., 2016, 62, 613-622.

203 Commonly used dialyzer specifications and substitution chart for visiting patients, http:/www.bcrenalagency.ca/ resource-gallery/Documents/Commonly\%20Used\%20Dialy zer\%20Specifications\%20and\%20Subs\%20Chart.pdf, (accessed September 11, 2019).

204 P. Schuff-Werner and B. Holdt, Artif. Organs, 2002, 26, 117-123.

205 W. Samtleben, S. Bengsch, K.-S. Boos and D. Seide, Artif. Organs, 1998, 22, 43-46.

206 N. Hirata, Y. Shizume, J. Shirokaze, J. Suemitsu, H. Yoshida and N. Yamawaki, Ther. Apher. Dial., 2003, 7, 64-68.

207 M. Onishi, K. Shimura, Y. Seita and S. Yamashita, Radiat. Phys. Chem., 1995, 46, 219-223.

208 Q. Xia, Y. Yun, Q. Li, Z. Huang and Z. Liang, Des. Monomers Polym., 2016, 20, 201-209.

209 Filtryzer BG Hemodialyzer, https://www.toray-medical. com/en/products/dialysis/detail.html?key=0EB5426D0F D8A757492580D20022E798, (accessed December 30, 2020).

210 J. M. Campistol, J. V. Torregrosa, E. Ponz and B. Fenollosa, in Polymethylmethacrylate. A Flexible Membrane for a Tailored Dialysis, ed. C. Ronco, Karger, Basel, 1998, vol. 125, pp. 76-85.

211 I. Iizuka, Z. Yamazaki, Y. Fujimori, T. Takahama, F. Kanai, T. Wada, N. Inoue, T. Sonoda, T. Nogi and M. Kimura, Ther. Apher., 2000, 4, 54-57.

212 D. Xie, L. Howard and R. Almousa, J. Biomater. Appl., 2018, 33, 340-351.

213 S. Kim, B. Feinberg, R. Kant, B. Chui, K. Goldman, J. Park, W. Moses, C. Blaha, Z. Iqbal, C. Chow, N. Wright, W. H. Fissell, A. Zydney and S. Roy, PLoS One, 2016, 11, e0159526.

214 N. J. Kaleekkal, D. Rana and D. Mohan, RSC Adv., 2016, 6, 63156-63170.

215 K. Togo, M. Yamamoto, M. Imai, K. Akiyama and A. C. Yamashita, Ren. Replace. Ther., 2018, 4, 29. 